Article

Subscriber access provided by The Bodleian Libraries of the University of Oxford

\title{
Mapping the Hydrophobic Substrate Binding Site of Phenylalanine Ammonia Lyase from Petroselinum crispum
}

Emma Zsófia Aletta Nagy, Souad Diana Tork, Pauline A. Lang, Alina Filip, Florin Dan Irimie, László Poppe, Monica loana To\#a, Christopher J. Schofield, Jürgen Brem, Csaba Paizs, and Laszlo Csaba Bencze

ACS Catal., Just Accepted Manuscript • DOI: 10.1021/acscatal.9b02108 • Publication Date (Web): 13 Aug 2019

Downloaded from pubs.acs.org on August 21, 2019

\section{Just Accepted}

"Just Accepted" manuscripts have been peer-reviewed and accepted for publication. They are posted online prior to technical editing, formatting for publication and author proofing. The American Chemical Society provides "Just Accepted" as a service to the research community to expedite the dissemination of scientific material as soon as possible after acceptance. "Just Accepted" manuscripts appear in full in PDF format accompanied by an HTML abstract. "Just Accepted" manuscripts have been fully peer reviewed, but should not be considered the official version of record. They are citable by the Digital Object Identifier (DOI®). "Just Accepted" is an optional service offered to authors. Therefore, the "Just Accepted" Web site may not include all articles that will be published in the journal. After a manuscript is technically edited and formatted, it will be removed from the "Just Accepted" Web site and published as an ASAP article. Note that technical editing may introduce minor changes to the manuscript text and/or graphics which could affect content, and all legal disclaimers and ethical guidelines that apply to the journal pertain. ACS cannot be held responsible for errors or consequences arising from the use of information contained in these "Just Accepted" manuscripts. 


\title{
Mapping the Hydrophobic Substrate Binding Site of Phenylalanine Ammonia-Lyase from Petroselinum
}

\author{
crispum
}

\author{
Emma Z. A. Nagy' t, Souad D. Tork ${ }^{1}$ t, Pauline A. Lang ${ }^{3}$, Alina Filip', Florin D. Irimie', \\ László Poppe², Monica I. Toșa', Christopher J. Schofield', Jürgen Brem³, Csaba \\ Paizs $^{1 *}$, László C. Bencze ${ }^{1 *}$
}

\author{
${ }^{1}$ Biocatalysis and Biotransformation Research Center, Faculty of Chemistry and \\ Chemical Engineering, Babe $\square$-Bolyai, University of Cluj-Napoca, Arany János Str. 11, \\ RO-400028 Cluj-Napoca, Romania.
}

2Department of Organic Chemistry and Technology, Budapest University of Technology and Economics, Mủegyetem rkp. 3. H-1111, Budapest, Hungary.

${ }^{3}$ Department of Chemistry, University of Oxford, Chemistry Research Laboratory, 12 Mansfield Road, Oxford, OX1 3TA, United Kingdom. 
$\dagger$ These authors contributed equally to this work.

*Address for correspondence: Dr. László Csaba Bencze, Prof. Dr. Paizs Csaba; Email:

cslbencze@chem.ubbcluj.ro,paizs@chem.ubbcluj.ro

\begin{abstract}
Modification of the hydrophobic binding pocket of phenylalanine ammonia-lyase from

Petroselinum crispum (PCPAL) enables increased activity and selectivity towards phenylalanines and cinnamic acids mono-substituted with both electron donating $\left(-\mathrm{CH}_{3}\right.$, $\left.-\mathrm{OCH}_{3}\right)$ and electron withdrawing $\left(-\mathrm{CF}_{3},-\mathrm{Br}\right)$ groups at all positions $(o-, m-, p-)$ of their aromatic ring. The results reveal specific residues involved in accommodating substituents at $0-, m-, p$-positions of the substrate's phenyl ring. The predicted interactions were validated by crystallographic analysis of the binding mode of paramethoxy cinnamic acid complexed at the active site of PCPAL. The biocatalytic utility of the tailored PCPAL mutants was demonstrated by the efficient preparative scale synthesis of (S)-m-bromo-phenylalanine (ee: $>99 \%$, yield: $60 \%$ ) and $(R)$ - $p$-methyl-
\end{abstract}




\begin{abstract}
phenylalanine (ee: $97 \%$, yield: $49 \%$ ), using the corresponding ammonia addition and ammonia elimination reactions catalyzed by the L134A and I460V PCPAL variants, respectively. Overall, the results reveal the potential for structure based protein engineering of PALs to provide enzymes with enhanced catalytic properties and which are specifically tailored for differently substituted phenylalanine analogues of high synthetic value.
\end{abstract}

Keywords: biocatalysis; protein engineering; phenylalanine ammonia-lyases; active site modification; D- and L-phenylalanine analogues

\author{
Introduction \\ Unnatural amino acids are valuable building blocks for the pharmaceutical and \\ agrochemical industries. They are also increasingly being incorporated into proteins and \\ peptides $^{1,2}$. Phenylalanine analogues have been successfully incorporated into
}


peptidomimetics aimed at addressing the increasing antimicrobial resistance ${ }^{3-5}$, as well those with antifungal properties ${ }^{6}$ and oxytocin analogues ${ }^{7}$.

Phenylalanine ammonia-lyases (PALs, EC 4.3.1.24/25) have considerable potential as biocatalysts for the production of optically pure D- and L-phenylalanine derivatives, ${ }^{8}$ as demonstrated by the implementation of PAL-based industrial processes such as the multi-ton scale production of (S)-2,3-dihydro-1H-indole-2-carboxylic acid by DSM (Netherlands). ${ }^{9}$

Phenylalanine ammonia-lyase from Petroselinum crispum (PCPAL) is amongst the most studied PALs and has been used in both ammonia addition and elimination reactions (Figure 1a), providing a wide range of L- and D-phenylalanine analogues. ${ }^{10-14}$ The substrate scope of PCPAL has been significantly extended to bulky substituents located, especially at the para-position of the substrate's aromatic ring, by individual and combined substitutions of the active site residues 1460 and F137.15 Previous substitutions of sequence-analogous residues for 1460 and F137 have been shown to change the substrate selectivities of phenylalanine and tyrosine ammonia-lyases (PAL/TAL), providing variants with increased PAL-activity. ${ }^{16,17}$ 
Inspired by these results, we directed interest towards exploring possible spatial orientations of differently positioned, ortho- (o-), meta- (m-), para- ( $p-)$ substituents of the substrate, towards neighboring active site residues (Figure 1b). We envisaged that identification and modification of PCPAL residues responsible for the active accommodation of the substrate's ring-substituents, would enable tailoring of the PCPAL towards non-natural substrates of high synthetic value that are poorly transformed by wild-type PALs.

Several studies on engineered PALs have recently been reported, including ones focusing on tailoring towards accommodating the p-substituted and/or bulky substrates $^{15,18,19}$ or substrates with electron donating groups ${ }^{20}$ and extended aliphatic chain $^{21}$. However, to our knowledge no systematic studies have been carried out on correlations between the position (i.e. $o^{-}, m-, p$-) of the substrate aryl ring substituent and specific active site residues involved in the aryl ring accommodation. 


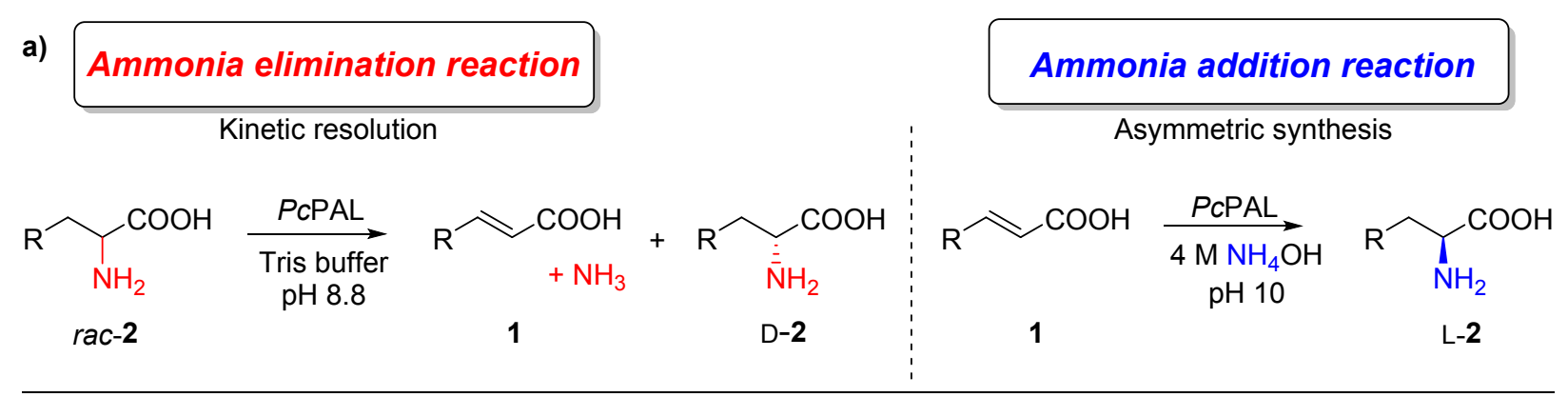

b)

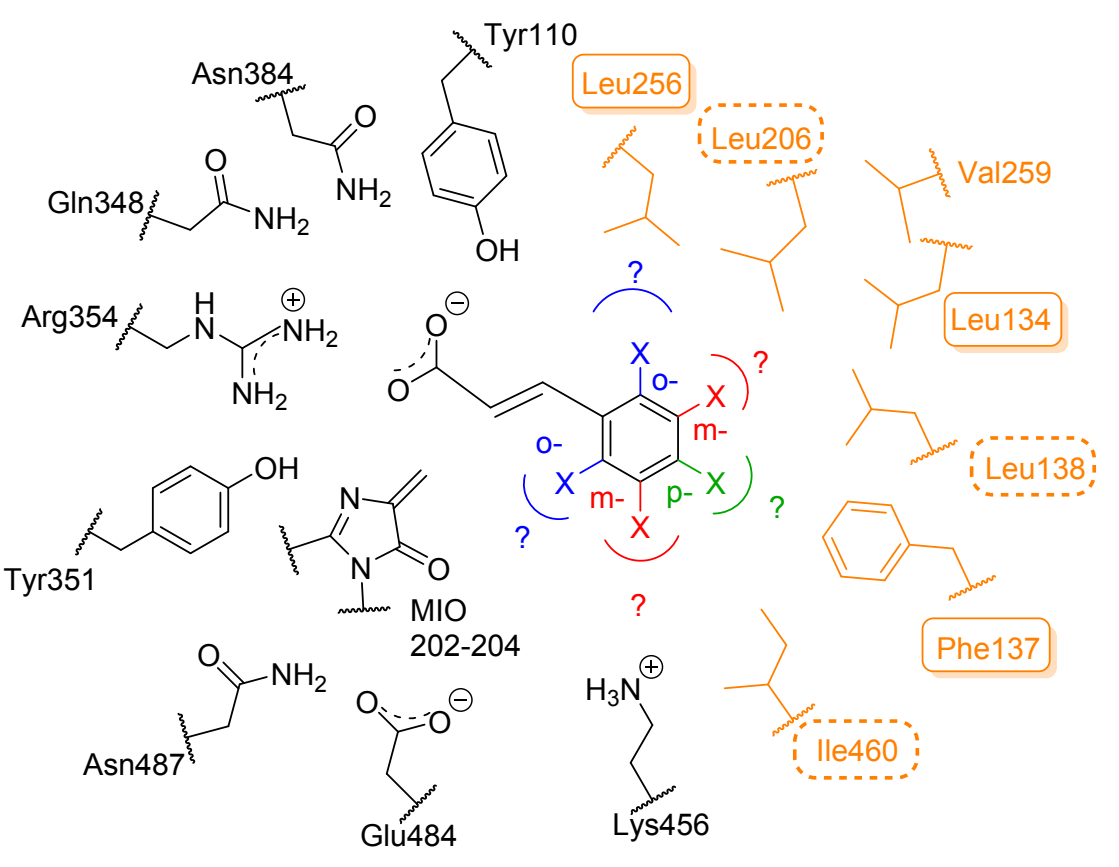

Figure 1. PCPAL catalysis and active site residues a) Ammonia addition and elimination reactions catalyzed by PCPAL. b) An active site model of $P C P A L^{15,22}$ (PDB ID: 1W2723) with modeled trans-cinnamic acid indicating possible interactions with the hydrophobic binding pocket (orange). Predicted orientations of aryl ring substituents are blue (ortho), red (meta-), and green (para-). The post-translationally produced 3,5-dihydro-5methylene-4H-imidazol-4-one (MIO) prosthetic group and the polar region of active site 
is also shown (black). Residues placed in boxes were selected for alanine and valine scanning with the aim of accommodating of ring substituents. Side chains in dashed boxes are positioned below the plane of the substrate's aromatic ring, while those with normal boxes are positioned above this plane.

\section{Results and Discussion}

\section{Mutagenesis of the hydrophobic binding pocket}

Prior to this work no structure of PCPAL with a substrate/product complexed had been reported, moreover, the only eukaryotic PAL structure with a bound product (PAL from Rhodosporidium toruloides - PDB ID: 1T6J), manifests 'relatively weak' and 'incomplete' electron density for the trans-cinnamic acid ligand ${ }^{24}$. In order to inform on the active site orientations of substituents attached to the aromatic ring of the substrate we employed a systematic mutational analysis of the hydrophobic substrate binding pocket of our PCPAL model. ${ }^{15,21,22}$

First, a set of PCPAL single mutants was prepared, by the individual replacement of all the residues of the hydrophobic binding pocket of the active site (Figure 1b, Table S1), 
to less sterically demanding alanine $(A)$ and/or valine $(V)$ residues, aiming to increase the volume available for substrates with ring substituents. All these substitutions have been found to be non-essential for PAL-activity ${ }^{15}$, and - despite decreasing the original PAL-activity in the natural reaction (ammonia elimination from L-Phe, Table S2) substantially increased the activities for different bulky, unnatural substrates. ${ }^{15,21}$ Modifications of active site residues from the polar active site region were omitted, since R354 (fixing the carboxylate of substrate), E484 (and presumably also their neighboring, 'counter-ion' residues Q348, K456) are involved in a H-bonding network that is essential for activity ${ }^{18,25}$. Y110 and Y351 were also shown to be essential within the MIO-group assisted reaction mechanism ${ }^{26,27}$. Besides the substitutions of the selected active site residues, the C704S and C716S substitutions of surface cysteines were also present within all tested PAL variants ${ }^{28}$, with the aim of decreasing aggregation tendency during isolation and crystallization of recombinant PALs ${ }^{28,29}$.

\section{Substrate library}

To explore the correlation between the position of the aromatic substituent and of the catalytically beneficial mutation of the hydrophobic substrate binding pocket (Figure 1b), 
we searched for substrates substituted at different positions of the aromatic ring, that are challenging to be transformed by the wt-PALs. Substrates with electron donating substituents are poorly converted, if at all, by wt-PALs, while $p$-substituted substrates with electron withdrawing and bulky substrates $\left(p-\mathrm{Br}-, \quad p-\mathrm{NO}_{2}-\mathrm{Phe}\right)$ present steric clashes with catalytic residues of wt-PALs ${ }^{15,18,19}$. Accordingly, for testing the PAL-activity of the mutant library, cinnamic acid and phenylalanine analogues, mono-substituted at all positions $(o-, m-, p-)$ of the aromatic ring with either electron donating $\left(-\mathrm{CH}_{3},-\mathrm{OCH}_{3}\right)$ or electron withdrawing $\left(-\mathrm{CF}_{3},-\mathrm{Br}\right)$ substituents, were investigated as substrates (Figure 2).
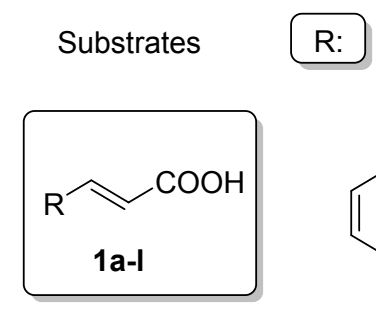

Electron donating groups Electron withdrawing groups<smiles>Cc1ccccc1C</smiles><smiles>Cc1cccc(C)c1</smiles>

b<smiles>Cc1ccc(C)cc1</smiles>

C<smiles>[R]CC(N)C(=O)OCCCC(=O)O</smiles><smiles>COc1ccccc1C</smiles><smiles>COc1cccc(I)c1</smiles><smiles>COc1ccc(C)cc1</smiles><smiles>Cc1ccccc1Br</smiles><smiles>Cc1cccc(Br)c1</smiles><smiles>Cc1ccc(Br)cc1</smiles> 
Figure 2. Substrates with monosubstituted phenyl moieties bearing electron donating or electron withdrawing groups in all positions of the aromatic ring for probing the PCPAL mutant library.

\section{PCPAL mediated biotransformations}

Initially, the set of PCPAL single mutants was screened for ammonia addition and ammonia elimination reactions of substrates 1a-I and rac-2a-I (see Tables S3-S26 for results of all PCPAL mutants tested). The PCPAL single mutants which showed the highest conversions were identified and used in further selectivity screens. In the subsequent tests, besides the conversions of substrates, the enantiomeric excesses $\left(e e_{p}\right)$ of products were also monitored (Tables 1-3).

Overall, despite the substantial differences between the reaction medium of the ammonia addition (4-6 $\mathrm{M} \mathrm{NH}_{3}, \mathrm{pH} 10$, buffered with $\mathrm{CO}_{2}$ ) and ammonia elimination (Tris. $\mathrm{HCl}, \mathrm{pH}$ 8.8) reactions, similar mutations provided enhanced catalytic properties in both types of reaction (Tables 1-3). This observation suggests that the hydrophobic pocket of the active site adopts a similar fold relative to the substrate in both reaction 
types. Thus, it is reasonable to propose that crystal structures obtained in a low ammonia environment can be used for the rational design of PALs with increased efficiency in the synthetically more important ammonia addition reaction. The electronic effects of different $\sigma$ and $m$-substituents provided no significant influence on enzyme activity (Table 1 and 2). In case of $p$-substitutions, in accordance with recent reports using PAL from Planctomyces brasiliensis ${ }^{20}$, substrates with electron donating groups $(1 \mathrm{c}, \mathrm{f}$ and rac-2c,f) clearly underperformed in the PCPAL-catalyzed reactions, when compared to substrates with electron withdrawing groups (1i,I and rac-2i,I) (Table 3).

More specifically, in the case of $o$-substituted substrate analogues wt-PCPAL was an efficient catalyst, suggesting that accommodation of, at least, moderately sized (Me-, $\mathrm{CF}_{3^{-}}$and $\mathrm{Br}-\mathrm{o}^{\mathrm{a}}$-substituents in the hydrophobic binding site is not sterically hindered in wt-PCPAL (Table 1). However, mutation of L256 in PCPAL to smaller side-chain amino acids resulted in higher conversions of $o$-substituted substrates in both reaction types, suggesting its interference with the o-substituents on binding of the substrate to the active site. One exception is the case of $o$-methoxy substituted substrates $1 \mathrm{~d}$ and rac$2 \mathrm{~d}$, where in comparison to the wt-PCPAL only the L134A and L134V variants provided 
significantly increased conversions, supporting a spatial orientation of the o-methoxy methyl group towards residue 134 .

Table 1. Conversion and enantiomeric excess values for the ammonia addition and elimination reactions catalyzed by wild-type and the three best performing mutant PCPALs in case of substrates with an $o$-substituted phenyl ring.

\begin{tabular}{|c|c|c|c|c|c|c|c|c|c|c|c|}
\hline \multicolumn{6}{|c|}{ Ammonia addition* } & \multicolumn{6}{|c|}{ Ammonia elimination* } \\
\hline \multicolumn{6}{|c|}{ Substrate / EWG } & \multicolumn{6}{|c|}{ Substrate / EWG ${ }^{\mathrm{a}}$} \\
\hline \multicolumn{3}{|c|}{$\mathbf{1 j} / o-\mathrm{Br}$} & \multicolumn{3}{|c|}{$\mathrm{1g} / o-\mathrm{CF}_{3}$} & \multicolumn{3}{|c|}{$r a c-2 \mathbf{j} / o-\mathrm{Br}$} & \multicolumn{3}{|c|}{$\mathrm{rac}-\mathbf{2} \mathrm{g} / \mathrm{o}-\mathrm{CF}_{3}$} \\
\hline PcPAL & $\mathbf{c} \%$ & $\mathbf{e e}_{(S)-2}$ & PcPAL & $\mathrm{c} \%$ & $\mathbf{e e}_{(S)-2}$ & PcPAL & $\mathbf{c \%}$ & $\mathbf{e e}_{(R)-2}$ & PcPAL & $\mathbf{c} \%$ & $\mathbf{e e}_{(R)-2}$ \\
\hline L256V & 91.5 & $>99$ & $\mathrm{~L} 134 \mathrm{~A}$ & 78.4 & $>99$ & $\mathrm{~L} 256 \mathrm{~V}$ & 49.1 & 97.2 & L256V & 50.8 & $>99$ \\
\hline L256A & 89.8 & $>99$ & L256V & 77.6 & $>99$ & $\mathrm{~L} 256 \mathrm{~A}$ & 44.8 & 84.8 & L206V & 51.8 & $>99$ \\
\hline$w t$ & 89.0 & $>99$ & $w t$ & 76.2 & $>99$ & $\mathrm{I} 460 \mathrm{~V}$ & 44.7 & 79.3 & L256A & 50.0 & $>99$ \\
\hline F137V & 85.9 & $>99$ & L206V & 76.1 & $>99$ & $w t$ & 42.0 & 72.4 & $w t$ & 49.0 & 94.0 \\
\hline \multicolumn{6}{|c|}{ Substrate / EDG ${ }^{b}$} & \multicolumn{6}{|c|}{ Substrate / EDG ${ }^{b}$} \\
\hline \multicolumn{3}{|c|}{$\mathbf{1 a} / o-\mathrm{CH}_{3}$} & \multicolumn{3}{|c|}{$\mathbf{1 d} / o-\mathrm{OCH}_{3}$} & \multicolumn{3}{|c|}{$\mathrm{rac}-\mathbf{2} \mathbf{a} / o-\mathrm{CH}_{3}$} & \multicolumn{3}{|c|}{$r a c-\mathbf{2 d} / o-\mathrm{OCH}_{3}$} \\
\hline PcPAL & $\mathbf{c \%}$ & $\mathbf{e e}_{(S)-2}$ & PcPAL & $\mathrm{c \%}$ & $\mathbf{e e}_{(S)-2}$ & PcPAL & $\mathbf{c \%}$ & $\mathbf{e e}_{(R)-2}$ & PcPAL & $\mathbf{c \%}$ & $\mathbf{e \mathbf { e } _ { ( R ) - 2 }}$ \\
\hline L256V & 62.1 & $>99$ & L134A & 47.9 & $>99$ & L256V & 54.9 & $>99$ & L134A & 29.3 & 41.1 \\
\hline$w t$ & 54.3 & $>99$ & L134V & 18.5 & $>99$ & $w t$ & 52.8 & $>99$ & $\mathrm{I} 460 \mathrm{~V}$ & 1.3 & 1.3 \\
\hline L134A & 52.4 & $>99$ & L206V & 5.7 & $>99$ & $\mathrm{I} 460 \mathrm{~V}$ & 50 & $>99$ & $w t$ & 1.0 & 1.1 \\
\hline $\mathrm{I} 460 \mathrm{~V}$ & 47.4 & $>99$ & $w t$ & $<1$ & - & $\mathrm{I} 460 \mathrm{~A}$ & 38.6 & 62.8 & L256A & $<1$ & - \\
\hline
\end{tabular}

* Reactions were performed under the conditions of biotransformation screenings (see Experimental Section)

a - Electron withdrawing group; ${ }^{b}$ - Electron donating group 
The proposed orientation of the $0-\mathrm{OCH}_{3}$ substituent towards $\mathrm{L} 134$ is further supported by the low conversions of $m$-substituted substrates when using the wild-type PCPAL (Table 2), with the exception of moderate conversions of $m$-bromo-substituted substrates $1 \mathbf{k}$ and rac-2k. Indeed, as for $0-\mathrm{OCH}_{3}$-substituted substrates $1 \mathbf{d}$ and rac-2d, the L134A variant provided significantly improved conversions compared to wt-PCPAL for all the $m$-substituted substrates (Table 2).

Unexpectedly, PCPAL I460V - reported recently as improved mutant variant for $p$ substituted substrate analogues ${ }^{15}$ - also enhanced the catalytic properties of the enzyme to a similar degree and even surpassing L134A, in terms of activity and/or selectivity in the case of $1 \mathrm{k}, 1 \mathrm{~h}$ and rac-2h, bearing electron withdrawing groups $(-\mathrm{Br}$, $\mathrm{CF}_{3}$ ) as substituents. These results support our model (Figure $1 \mathrm{~b}$ ), in which substitution of either residues L134 or 1460 could provide more space for $m$-substituents; moreover, the presence of the polar residue K456 in proximity of 1460 , might contribute to the observed higher transformation rates of substrates bearing polar $m$-substituents, when using mutant I460V. 
Table 2. Conversion and enantiomeric excess values for the ammonia addition and elimination reactions catalyzed by wild-type and the three best performing mutant PCPALs in case of substrates with a $m$-substituted phenyl ring.

\begin{tabular}{|c|c|c|c|c|c|c|c|c|c|c|c|}
\hline \multicolumn{6}{|c|}{ Ammonia addition* } & \multicolumn{6}{|c|}{ Ammonia elimination* } \\
\hline \multicolumn{6}{|c|}{ Substrate / EWGa } & \multicolumn{6}{|c|}{ Substrate / EWGa } \\
\hline \multicolumn{3}{|c|}{$1 \mathbf{k} / m-\mathrm{Br}$} & \multicolumn{3}{|c|}{$\mathbf{1 h} / m-\mathrm{CF}_{3}$} & \multicolumn{3}{|c|}{$r a c-2 \mathbf{k} / m-\mathrm{Br}$} & \multicolumn{3}{|c|}{$\mathrm{rac}-\mathbf{2 h} / \mathrm{m}-\mathrm{CF}_{3}$} \\
\hline PcPAL & c\% & $\mathbf{e e}_{(S)-2}$ & PcPAL & $\mathrm{c \%}$ & $\mathbf{e e}_{(S)-2}$ & PcPAL & c\% & $\mathbf{e \mathbf { e } _ { ( R ) - 2 }}$ & PcPAL & c\% & $\overline{\mathbf{e e}_{(R)-2}}$ \\
\hline L134A & 79.6 & 99 & $\mathrm{I} 460 \mathrm{~V}$ & 36.9 & $>99$ & $\mathrm{~L} 134 \mathrm{~A}$ & 48.9 & 94.1 & $\mathrm{I} 460 \mathrm{~V}$ & 31.4 & 49.5 \\
\hline $\mathrm{I} 460 \mathrm{~V}$ & 68 & $>99$ & L134A & 17.5 & $>99$ & $\mathrm{I} 460 \mathrm{~V}$ & 42.4 & 77.8 & L134A & 26.2 & 38.5 \\
\hline $\mathrm{I} 460 \mathrm{~A}$ & 29.6 & $>99$ & $\mathrm{~L} 138 \mathrm{~V}$ & 11.1 & $>99$ & $w t$ & 31.4 & 47.0 & $w t$ & 9.1 & 9.9 \\
\hline$w t$ & 28.9 & $>99$ & $w t$ & $<1$ & - & $\mathrm{F} 137 \mathrm{~V}$ & 24.5 & 33.0 & $\mathrm{~F} 137 \mathrm{~V}$ & 6.9 & 7.5 \\
\hline \multicolumn{6}{|c|}{ Substrate / EDG ${ }^{\mathrm{b}}$} & \multicolumn{6}{|c|}{ Substrate / $E D G^{\mathrm{b}}$} \\
\hline \multicolumn{3}{|c|}{$\mathbf{1 b} / m-\mathrm{CH}_{3}$} & \multicolumn{3}{|c|}{ 1e $/ m-\mathrm{OCH}_{3}$} & \multicolumn{3}{|c|}{$\mathrm{rac}-\mathbf{2 b} / m-\mathrm{CH}_{3}$} & \multicolumn{3}{|c|}{$\mathrm{rac}-\mathbf{2 e} / \mathrm{m}-\mathrm{OCH}_{3}$} \\
\hline PcPAL & $\mathbf{c \%}$ & $\mathbf{e e}_{(S)-2}$ & PcPAL & c\% & $\mathbf{e e}_{(S)-2}$ & PcPAL & c\% & $\mathbf{e e}_{(R)-2}$ & PcPAL & $\mathrm{c} \%$ & $\mathbf{e e}_{(R)-2}$ \\
\hline L134A & 22.7 & $>99$ & L134A & 73.0 & $>99$ & $\mathrm{~L} 134 \mathrm{~A}$ & 23.8 & 31.2 & $\mathrm{~L} 134 \mathrm{~A}$ & 51.2 & $>99$ \\
\hline $\mathrm{I} 460 \mathrm{~V}$ & 12.7 & $>99$ & F137V & 24.5 & $>99$ & $\mathrm{I} 460 \mathrm{~V}$ & 14.6 & 20.4 & L134V & 29.5 & 40.3 \\
\hline L134V & 9.8 & $>99$ & $w t$ & 16.9 & $>99$ & L134V & 9.1 & 10.2 & $w t$ & 16.1 & 20.2 \\
\hline$w t$ & 4.9 & $>99$ & $\mathrm{I} 460 \mathrm{~V}$ & 4.2 & $>99$ & $w t$ & 7.1 & 7.7 & $\mathrm{I} 460 \mathrm{~V}$ & 7.9 & 8.7 \\
\hline
\end{tabular}

* Reactions were performed under the conditions of biotransformation screenings (see Experimental Section)

a - Electron withdrawing group; ${ }^{b}$ - Electron donating group

The low or moderate conversions obtained with wt-PCPAL in the case of $p$ substituted substrates (Table 3 ) is consistent with a steric clash between $p$-substituent and active site residues, as described in previous reports ${ }^{15,18}$. Two mutants, namely 
F137V and 1460V, proved to be superior in terms of conversions (Table 3). With the substrates $p$-substituted with EWG (e.g. for 1 l and 1i), higher conversions could be achieved with the F137V variant than with the I460V mutant; however PCPAL F137V provided incomplete enantiotopic selectivity, while enantiopure products (ee $>$ $>99 \%$ ) resulted when using PCPAL 1460V

Table 3. Conversion and enantiomeric excess values for the ammonia addition and elimination reactions catalyzed by wild-type and the three best performing mutant PCPALs in case of substrates with a $p$-substituted phenyl ring.

\begin{tabular}{|c|c|c|c|c|c|c|c|c|c|c|c|}
\hline \multicolumn{6}{|c|}{ Ammonia addition* } & \multicolumn{6}{|c|}{ Ammonia elimination* } \\
\hline \multicolumn{6}{|c|}{ Substrate / EWG ${ }^{a}$} & \multicolumn{6}{|c|}{ Substrate / EWG } \\
\hline \multicolumn{3}{|c|}{$11 / p-\mathrm{Br}$} & \multicolumn{3}{|c|}{$\mathbf{1 i} / p-\mathrm{CF}_{3}$} & \multicolumn{3}{|c|}{$\mathrm{rac}-\mathbf{2 1} / \mathrm{p}-\mathrm{Br}$} & \multicolumn{3}{|c|}{$\mathrm{rac}-\mathbf{2 i} / p-\mathrm{CF}_{3}$} \\
\hline PcPAL & $\mathrm{c \%}$ & $\mathbf{e e}_{(S)-2}$ & PcPAL & $\mathrm{c \%}$ & $\mathbf{e e}_{(S)-\mathbf{2}}$ & PcPAL & $\mathbf{c \%}$ & $\mathbf{e e}_{(R)-2}$ & PcPAL & $\mathrm{c \%} \%$ & $\mathbf{e e}_{(R)-2}$ \\
\hline $\mathrm{F} 137 \mathrm{~V}$ & 61.2 & 97 & F137V & 73.9 & 91.0 & $\mathrm{I} 460 \mathrm{~V}$ & 49.8 & $>99$ & F137V & 48.8 & 81.5 \\
\hline $\mathrm{I} 460 \mathrm{~V}$ & 51.1 & $>99$ & $\mathrm{I} 460 \mathrm{~V}$ & 20.4 & $>99$ & F137V & 45.0 & 95.9 & $\mathrm{I} 460 \mathrm{~V}$ & 36 & 51.7 \\
\hline L138V & 13.2 & $>99$ & F137A & 16.6 & $>99$ & $w t$ & 34.2 & 54.3 & F137A & 30.1 & 42.2 \\
\hline$w t$ & 7.6 & $>99$ & $w t$ & 5.7 & $>99$ & L206V & 7.9 & 8.6 & $w t$ & 5.9 & 6.3 \\
\hline \multicolumn{6}{|c|}{ Substrate / EDG ${ }^{b}$} & \multicolumn{6}{|c|}{ Substrate / EDG ${ }^{\mathrm{b}}$} \\
\hline \multicolumn{3}{|c|}{$\mathbf{1 c} / p-\mathrm{CH}_{3}$} & \multicolumn{3}{|c|}{$\mathbf{1 f} / p-\mathrm{OCH}_{3}$} & \multicolumn{3}{|c|}{$r a c-2 c / p-\mathrm{CH}_{3}$} & \multicolumn{3}{|c|}{$r a c-\mathbf{2 f} / p-\mathrm{OCH}_{3}$} \\
\hline PcPAL & c\% & $\mathbf{e e}_{(S)-2}$ & PcPAL & $\mathbf{c \%}$ & $\mathbf{e e}_{(S)-2}$ & PcPAL & $\mathrm{c \%}$ & $\mathbf{e e}_{(R)-2}$ & PcPAL & $\mathrm{c \%}$ & $\mathbf{e e}_{(R)-2}$ \\
\hline F137V & 16.6 & $>99$ & $\mathrm{I} 460 \mathrm{~V}$ & 11.8 & $>99$ & $\mathrm{I} 460 \mathrm{~V}$ & 22.1 & 25.8 & F137V & 21 & 26.1 \\
\hline $\mathrm{I} 460 \mathrm{~V}$ & 16.2 & $>99$ & F137V & 5.4 & $>99$ & F137V & 10.7 & 23.8 & $\mathrm{I} 460 \mathrm{~V}$ & 16.8 & 19.1 \\
\hline L134V & 3.7 & $>99$ & L138A & 2.9 & $>99$ & $w t$ & 3.0 & 3.1 & $\mathrm{I} 460 \mathrm{~A}$ & 12.0 & 15.1 \\
\hline
\end{tabular}


* Reactions were performed under the conditions of biotransformation screenings (see Experimental Section) a - Electron withdrawing group; ${ }^{b}$ - Electron donating group

\section{Kinetic analyses}

Kinetic parameters $\left(\mathrm{K}_{\mathrm{M}}, \mathrm{k}_{\mathrm{cat}}, \mathrm{k}_{\mathrm{cat}} / \mathrm{K}_{\mathrm{M}}\right)$ determined for the best performing and wild-type $P c$ PAL variants in the ammonia elimination reactions of representative $o-, m-, p-\mathrm{CF}_{3^{-}}$ phenylalanines rac-2g,h,i, revealed valuable insights regarding the effect of mutations upon the catalytic efficiency of $P c$ PAL in the reactions of ring-substituted substrates (Table 4).

In conformity with the results of the whole cell biotransformations, the catalytic activities reflected by $\mathrm{k}_{\text {cat }}$ values for the best performing mutants incubated with rac-2g,h,i were significantly higher than those found for $w t-P c$ PAL. These data associated with increased $\mathrm{K}_{\mathrm{M}}$ values in case of $o-, m-\mathrm{CF}_{3}$-phenylalanines $\mathrm{rac}-\mathbf{2 g}, \mathbf{h}$, revealing the simultaneous increased activity and lowered affinity of the PcPAL mutants towards these substrates. Thus, in accordance with other similar studies ${ }^{21}$ a more relaxed arrangement of the substrate within the catalytic site for the tested mutant variants can be stated. As exception, I460V PcPAL displays significantly increased activity and affinity towards $m-\mathrm{CF}_{3}-\mathrm{Phe}$, which is consistent with the used model and, supports the proposed interaction of the electronwithdrawing substituents with residue K456, which is likely proximal to 1460 (Figure 1b).

In case of $p-\mathrm{CF}_{3}$-phenylalanine $r a c-2 \mathbf{i}$, compared to $w t-P c \mathrm{PAL}$, both mutant variants F137V and I460V displayed increased affinity and catalytic activity, resulting up to 27 fold improved catalytical efficiency $\left(\mathrm{k}_{\mathrm{cat}} / \mathrm{K}_{\mathrm{M}}\right)$ compared with $w t-P c \mathrm{PAL}$ (Table 4). For the ammonia elimination from $o-\mathrm{CF}_{3}-\mathrm{Phe}(\mathrm{rac}-2 \mathrm{~g})$, despite the high conversion values obtained with the L206V and $w t-P c$ PAL (52\% and 49\%, respectively, comparable with those for L256V (50\%) 
(Table 1)), mutant L256V presented a significantly higher $\mathrm{k}_{\text {cat }}$ (3.6 fold compared to wt- or L206V), albeit the kcat/Km values are in similar range for all three enzymes (61.7 for wt-, 64.8 for L206V and 54.2 for L256) (Table 4). These observations suggests that during long-term biotransformations besides intrinsic enzyme activity, other factors such as enzyme stability, solubility and product inhibition influence the conversion values.

Tabel 4. Kinetic parameters for the ammonia elimination reaction of $\mathrm{rac}-\mathbf{2} \mathbf{g}, \mathbf{h}, \mathbf{i}$.

\begin{tabular}{c|ccc|ccc|ccc}
\hline Compound & \multicolumn{3}{|c|}{$r a c-2 \mathrm{~g} / o-\mathrm{CF}_{3}$} & \multicolumn{3}{c|}{$r a c-2 \mathbf{h} / m-\mathrm{CF}_{3}$} & \multicolumn{3}{c}{$r a c-2 \mathbf{i} / p-\mathrm{CF}_{3}$} \\
$\boldsymbol{P c P A L}$ & $\boldsymbol{w t -}$ & $\mathbf{L 2 0 6 V}$ & $\mathbf{L 2 5 6 V}$ & $\boldsymbol{w t}$ & $\mathbf{I 4 6 0 V}$ & $\mathbf{L 1 3 4 V}$ & $\boldsymbol{w t}$ & $\mathbf{F 1 3 7 V}$ & $\mathbf{I 4 6 0 V}$ \\
\hline $\mathbf{K}_{\mathbf{M}}(\mu \mathrm{M})$ & 523 & 743 & 2733 & 533 & 163 & 912 & 2490 & 151 & 901 \\
$\mathbf{k}_{\text {cat }}\left(\mathrm{s}^{-1}\right)$ & 0.042 & 0.041 & 0.148 & 0.057 & 0.200 & 0.203 & 0.25 & 0.42 & 0.55 \\
$\begin{array}{c}\mathbf{k}_{\text {cat }} / \mathbf{K}_{\mathbf{M}} \\
\left(\mathrm{s}^{-1} \times \mathrm{M}^{-1}\right)\end{array}$ & 61.7 & 64.8 & 54.2 & 103.2 & 1227.0 & 222.8 & 100.4 & 2781.4 & 611.1 \\
\hline
\end{tabular}

Crystallization studies

To investigate whether our strategy had correctly identified the substrate substituent orientation relative to the hydrophobic residues in the active site of PCPAL active site, we pursued crystallographic analyses. These resulted in a crystal structure (resolution of $2.4 \AA$ ) of the l460V mutant liganded with $p$-methoxycinnamic acid $1 \mathrm{f}$ at the active site (PDB ID: 6RGS). As reported for $w t-P C P A L{ }^{23}, P C P A L ~ 1460 V$ crystallizes at neutral pH in the space group $C 222_{1}$ with two chains $(A, B)$ in the asymmetric unit, with symmetry related molecules making up a tetramer, as observed in solution ${ }^{23}$. 
The crystallographic tetramer contains four active sites and shows high similarity to the reported structure of $w t-P C P A L$ with an overall RMSD of 0.271 . Several loops could not be modeled, with two of the loops (residues 105-127 and 331-346) being close to the active site (Figure S34). These loops are proposed to be highly mobile and residues 105-127 have been proposed by Ritter et al. to be involved in catalysis ${ }^{23}$. In our structure we do not see evidence for the proposed ${ }^{23}$ induced fit of these loops upon substrate binding, though this may occur in solution.

Electron density was observed in one of the active sites corresponding to the presence of substrate 1f. Analysis of the binding mode of $p$-methoxycinnamic acid 1f in PCPAL I460V shows the para-position of the aromatic ring in close proximity of the substituted residue 460 . Overlay with the reported structure of the $w t-P c \mathrm{PAL}^{23}$ reveals a potential steric clash with the I460 side chain (Figures 3 and S35). It should, however be noted that significantly weaker electron density is observed in our structure for the methoxy group, compared to the rest of the molecule (Figure S37), likely indicating a degree of disorder for this substituent (resulting in an increase of B-factor by about $10 \%$ compared to the rest of the molecule). Nonetheless, in accord with our model (Figure 1b) and the biotransformation results, the structure suggests orientation of the methyl group of methoxy towards V460. The positions of the other hydrophobic active site residues (F137, L138, L134, L206 and L256) are very similar to those within our model (Figure 1b). An exception is K456, which is flanked between residues V460 and F137 (Figure 3), 
exposing the hydrophobic part of its side chain towards the $p$-and $m$-positions of the substrate. The missing electron density for the $\mathrm{NH}_{2}$ - group of $\mathrm{K} 456$ hinders the validation of the polar interactions with the $m-\mathrm{CF}_{3}$-substitutent, as proposed based on the biotransformation and enzyme kinetic data.

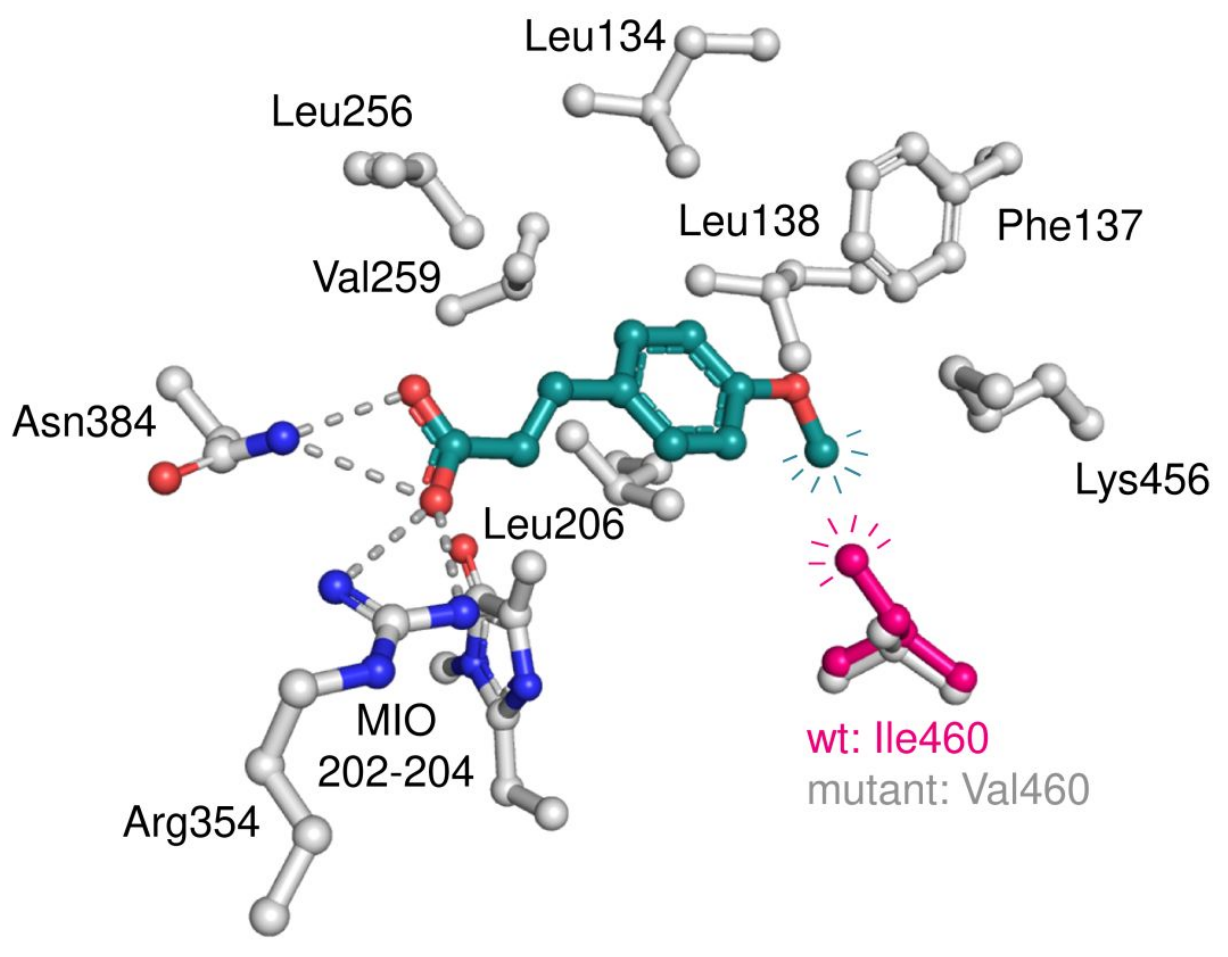

Figure 3: View of $p$-methoxy-cinnamic acid 1f at the active site of PCPAL 1460V (PDB ID: 6RGS). Side chains of active site residues (white) involved in substrate binding, including those in the hydrophobic pocket are shown. The side chain of 1460 as observed in the active site of wt-PCPAL (PDB ID: 1W27) is overlaid in magenta. The 
I460V substitution prevents the indicated steric clash of this side chain with the $p$ substituent of the substrate. See Figure S36 for full overlay of the two active sites.

Prior to our work no PAL structure with a ring substituted substrate-like ligand/product complexed in the active site has been reported. The structure of Rhodosporidium toruloides PAL (RIPAL) with trans-cinnamic acid bound to the active site (PDB ID: 1T6J), represented the only previously reported structure of fully catalytically viable PAL complexed with a substrate/product, albeit with the reported electron density corresponding to the ligand being non-optimal 24 . Although Weise et $a l^{30}$ have reported a structure of the Anabaena variabilis (ALPAL) bound to cinnamate (PDB ID: 5LTM), this represents a structure for a catalytically inactive Y78F-C503S-C565S mutant of a prokaryotic PAL. Overlay of the active sites of this structure and the structure of the I460V PCPAL-ligand complex reported here shows, although there is otherwise good agreement of the most active site residues, some differences in the binding-mode of the substrate carboxylate moiety, as well as in the orientation of R354 which is involved in the interaction with the substrate carboxylate, are manifest (Figure 4a and Figure S38). 
Comparison of our structure with that of cinnamate complexed with the structurally related phenylalanine aminomutase from Taxus canadensis (TCPAM) (PDB ID: 3NZ4 ${ }^{31}$ ) presents good agreement. However, there are shown minor differences in the substrate interactions. Interestingly, the $p$-methoxycinnamic acid $1 f$ ligand as observed in our structure would sterically clash with Y80 of TCPAM , the equivalent of Y110 in PCPAL, which has been proposed to be involved in catalysis and which was not observed in our structure (Figure $4 \mathrm{~b}$ and Figure S38).
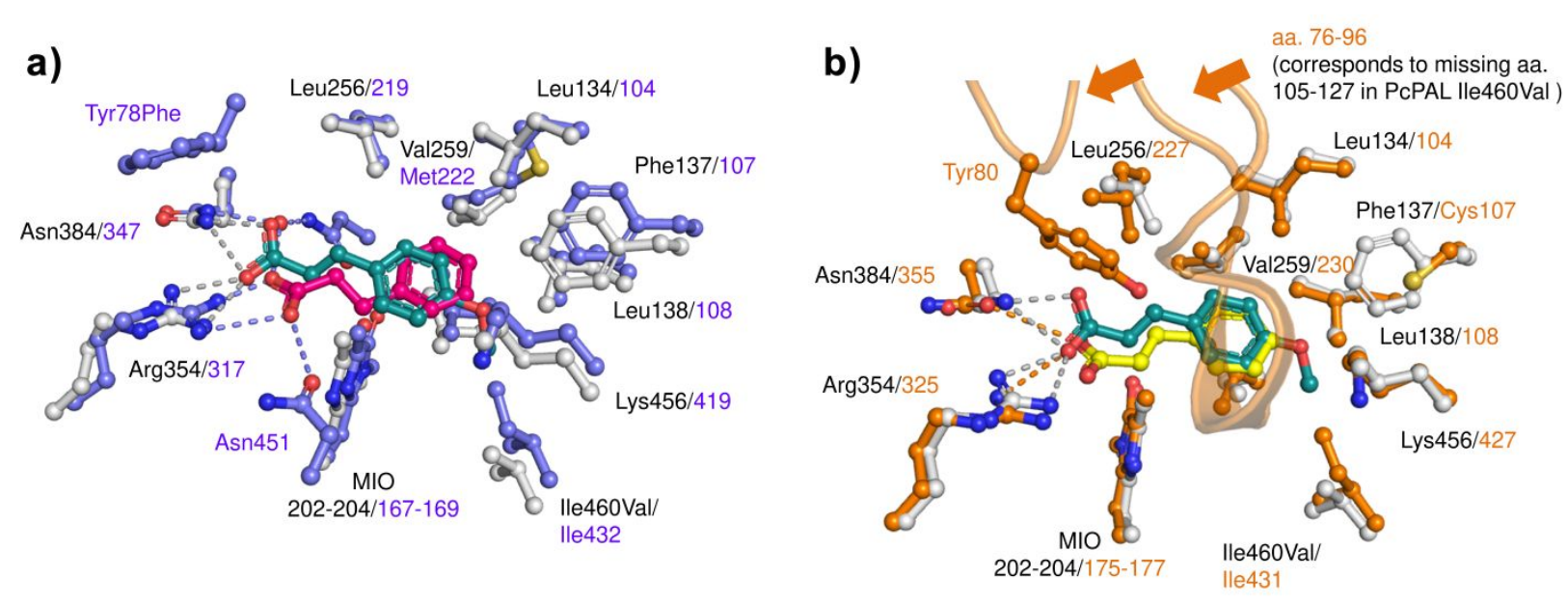

Figure 4. Overlay of active sites of I460V PcPAL $-p$-methoxy cinnamic acid 1f (cyan) complex and reported structures: a) overlay with structure of $\mathrm{Y} 78 \mathrm{~F} / \mathrm{C} 503 \mathrm{~S} / \mathrm{C} 565 \mathrm{~S} A v \mathrm{PAL}$ with "cinnamate", apparently refined into hydro-cinnamic acid (magenta) (PDB ID: 5LTM) ${ }^{30}$ b) 
overlay with the active site of TcPAM in complex with cinnamic acid (yellow) (PDB ID: 3NZ4) ${ }^{31}$, amino acids 76-96 are located in the active site and indicated as cartoon.

Although the present work is focused on biocatalytic application of PAL, the substrate complexed protein structure is of interest from a mechanistic perspective. Two general mechanisms for PAL have been proposed 25,26 : one involving reaction of a substrate amino group/ammonia with $\mathrm{MIO}$ and one involving reversible Friedel-Crafts type reaction at the ortho-position of the substrate aryl-ring. Whilst the solution situation is almost certainly more complex than manifested in static crystal structures, our structure is more consistent with the former mechanism. The distance from the MIO methylene carbon to the C-2 carbon of $p$-methoxycinnamic acid is $3.8 \AA$, (while the closest orthoposition of $p$-methoxycinnamic acid is located at a distance of $4.5 \AA$ ), suggesting the viability of the reaction of the substrate amino group with MIO.

\section{Synthetic applications}

To test the synthetic applicability of the PALs with improved catalytic properties, preparative scale biotransformations were attempted for production of phenylalanine derivatives of high synthetic interest. (S)-m-Bromo-phenylalanine $\mathrm{L}-\mathbf{2} \mathbf{k}$, through the 
amber suppression approach, has been used to expand the chemical diversity of bioactive peptides, such as lasso peptide microcin J25 (MccJ25) ${ }^{32}$ or $\mathrm{Cmpd}-15^{33}$, a negative allosteric modulator for the $\beta_{2}$-adrenergic receptor, while $(R)$ - $p$-methylphenylalanine D-2c has been incorporated in anti-inflammatory formyl peptide receptor 1 antagonists $^{34}$, as well as Pin1 inhibitors ${ }^{35}$ (Figure S39). To determine the optimal reaction times for the preparative scale reactions, we monitored the conversions and the enantiomeric excess of the product in the ammonia addition reactions of $m$-bromocinnamic acid $1 \mathrm{k}$ (Figure $5 \mathrm{a}$ ) and of the ammonia elimination from racemic $p$-methylphenylalanine rac-2c (Figure $5 \mathrm{~b}$ ). The reaction progress reached stationary phase at conversion values of $\sim 80 \%$ in case of ammonia addition onto $1 \mathrm{k}$ after 8 hours reaction, while the ammonia elimination from rac-2h reached the optimal $50 \%$ conversion of the kinetic resolution process after 50 hours reaction time. Both reactions were highly selective, the enantiomeric excess values of products approximated the theoretical maximum of a fully selective process (Figure $5 a, b$ ). The preparative scale reactions were performed on a $500 \mathrm{mg}$ scale, allowing the isolation of phenylalanine analogues 
$(S)-2 k$ and $(R)-2 \mathrm{c}$ in high yields $\left(49 \%\right.$ and $60 \%$, respectively) and optical purity $\left(\mathrm{ee}_{(\mathcal{S})-2 \mathrm{k}}\right.$ :

$>99 \%$ and $\left.e_{(R)-2 c}: 97 \%\right)$ (Figure S39).

a)

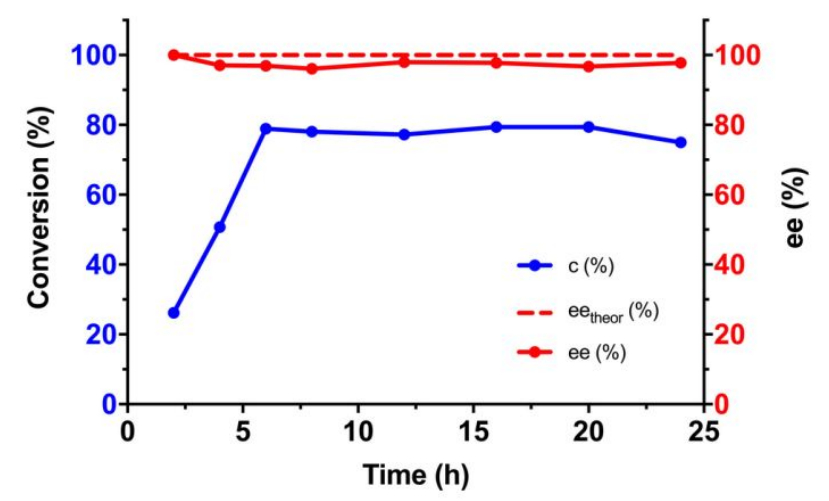

b)

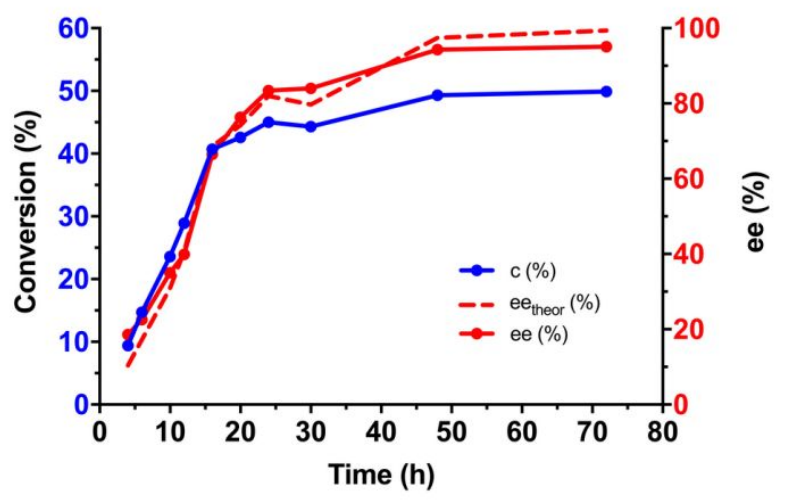

Figure 5. Conversion and enantiomeric excess progression curves for a) the ammonia addition onto $m$-Br-cinnamic acid $1 \mathrm{k}$ using L134A PCPAL and for $\mathrm{b}$ ) the ammonia elimination from rac-p-methyl-phenylalanine rac-2c using I460V PCPAL.

\section{Experimental Section}

Site-directed mutagenesis 
Mutant PAL genes were obtained through site-directed mutagenesis using wt-pcpal with $\mathrm{pET}-19 \mathrm{~b}$ vector as template. The protocol as well as the list of primers used for mutagenesis are provided in the Supporting Information.

\section{Protein production and purification}

The purification of the recombinant wild-type PCPAL (containing surface mutations C704S/C716S, shown to decrease the aggregation tendency of PALs ${ }^{29}$ ), and active site mutant variants with the additional C704S/C716S substitution were performed using the protocol described in our previous work ${ }^{28}$. The protein purity and homogeneity were determined using SDS-PAGE electrophoresis and size-exclusion chromatography.

\section{Whole cell-assay plate preparation}

The overnight preculture was prepared in a 2.2-ml 96-deep-well plate containing 600 $\mu \mathrm{L} /$ well of LB (Lysogenic Broth) medium supplemented with carbenicillin $(50 \mu \mathrm{g} / \mathrm{mL})$ and chloramphenicol (30 $\mu \mathrm{g} / \mathrm{mL})$ and inoculated with glycerol stocks of $E$. coli Rosetta (DE3) pLysS cells harbouring the pET19b vector carrying the $w t$ - or mutant $p a / g e n e$, followed by overnight incubation at $37^{\circ} \mathrm{C}$ and shaking at $200 \mathrm{rpm}$. 
The obtained preculture was further used to inoculate the assay plate with $1.2 \mathrm{~mL} /$ well of LB medium grown at $37{ }^{\circ} \mathrm{C}, 200 \mathrm{rpm}$ until $\mathrm{OD}_{600}$ reached $0.6-0.8$, at which point protein production was induced via the addition of $0.1 \mathrm{mM}$ IPTG (final concentration), and the cell growth was maintained at $25{ }^{\circ} \mathrm{C}$ for another $16 \mathrm{~h}$. Cell densities of $\mathrm{OD}_{600}$ were measured for each mutant variant and wild-type PCPAL, and duplicate wells were prepared containing cells of $\mathrm{OD}_{600}$ of $\sim 1$. The cells were harvested by centrifugation at $4000 \mathrm{rpm}(2270 \times \mathrm{g})$ and $4{ }^{\circ} \mathrm{C}$ for $20 \mathrm{~min}$ and washed with PBS buffer $(20 \mathrm{mM}$ phosphate, $150 \mathrm{mM} \mathrm{NaCl}, \mathrm{pH} 8.0)\left(4000 \mathrm{rpm}, 2270 \times \mathrm{g}, 4{ }^{\circ} \mathrm{C}, 20 \mathrm{~min}\right)$ and stored at $20{ }^{\circ} \mathrm{C}$ until further use.

Biotransformation screening using 96-well assay plates for ammonia elimination reactions

Initial screenings in case of the ammonia elimination reactions were measured in 96well UV-Microplates (Corning Inc.), using Tecan Infinite Spark 10M microplate reader. Stock solutions of $5 \mathrm{mM}$ substrate solutions of rac-2a-I were prepared in Tris-buffer (100 $\mathrm{mM}$ Tris- $\mathrm{HCl}, 120 \mathrm{mM} \mathrm{NaCl}, \mathrm{pH}$ 8.8) while using isolated wild-type and mutants PCPAL enzyme solutions. Reactions were done in triplicate at $30^{\circ} \mathrm{C}$ with the ratio of substrate 
concentration: biocatalysts of 1:0.005 (1 mM substrate and $5 \mu \mathrm{g}$ enzyme), monitoring the production of specific cinnamic acid analogues through absorbance at $290 \mathrm{~nm}$ (Tables S15-S26).

The first five PCPAL variants with the highest relative activity were selected for wholecell biotransformations, monitoring the conversions after $16 \mathrm{~h}$. In cases where the conversion-based ranking of PCPAL variants significantly differed from their relative activity-based order, the whole-cell biotransformations with all PCPAL variants were performed (Table S15-S26). Based on the obtained conversion values, the biotransformations of $w t-P C P A L$ and the three best performing mutant variants were further selected and the enantiomeric excess of D-2a-I products was also determined, resulting in data presented within Tables 1-3.

The whole cell biotransformations were performed in 96-well deep-well plates of $2.2 \mathrm{~mL}$, containing the whole cell PCPAL-biocatalysts, prepared as described above. The bacterial pellet was resuspended to an $\mathrm{OD}_{600}$ of $\sim 2$, in $200 \mu \mathrm{L}$ of Tris-buffer $(100 \mathrm{mM}$ Tris- $\mathrm{HCl}, 120 \mathrm{mM} \mathrm{NaCl}, \mathrm{pH}$ 8.8) solutions containing amino acids rac-2a-I in $2 \mathrm{mM}$ concentration. The plates were incubated at $30{ }^{\circ} \mathrm{C}, 250 \mathrm{rpm}$, samples were taken at 
different reaction times, were quenched by adding an equal volume of $\mathrm{MeOH}$, vortexed and centrifuged $(13400 \mathrm{rpm}, 12000 \times \mathrm{g}, 10 \mathrm{~min})$. The supernatant was filtered through a $0.22 \mu \mathrm{m}$ nylon membrane filter and analyzed by HPLC.

Biotransformation screening using 96-well assay plates for ammonia addition reactions

The screens for ammonia addition reactions were performed in duplicate using 96well deep-well plates of $2.2 \mathrm{~mL}$, containing the whole cell PCPAL-biocatalysts. The bacterial pellet was resuspended to an $\mathrm{OD}_{600}$ of $\sim 2$, in $200 \mu \mathrm{L}$ of $6 \mathrm{M} \mathrm{NH}_{4} \mathrm{OH}$ buffer $(\mathrm{pH}$ 10, adjusted with $\mathrm{CO}_{2}$ ) solutions containing cinnamic acids $1 \mathrm{a}-\mathrm{I}$ in $2 \mathrm{mM}$ concentration. The plates were incubated at $30{ }^{\circ} \mathrm{C}, 250 \mathrm{rpm}$. Conversions were monitored using reversed phase high performance liquid chromatography (HPLC). Samples taken at different reaction times, were quenched by adding an equal volume of $\mathrm{MeOH}$, vortexed and centrifuged $(13400 \mathrm{rpm}, 12000 \times \mathrm{g}, 10 \mathrm{~min})$. The supernatant was filtered through a $0.22 \mu \mathrm{m}$ nylon membrane filter and analyzed by HPLC (Tables S3-S14).

Kinetics measurements

Enzyme assays were carried out in triplicate at $30^{\circ} \mathrm{C}$ in 96 -well Corning UVmicroplates using $100 \mathrm{mM}$ Tris. $\mathrm{HCl}, 120 \mathrm{mM} \mathrm{NaCl}(\mathrm{pH}$ 8.8) as buffer, at constant 
concentration of the specific PCPAL $(0.3125 \mu \mathrm{M})$, varying the substrate concentrations from 0.025 and $8 \mathrm{mM}$, until substrate saturation occurred. The kinetic measurements were based on UV-spectroscopy by monitoring the production of the acrylic derivatives 2a-d for $10 \mathrm{~min}$, at wavelengths where the corresponding amino acids rac-1a-d showed no absorption (Table S29). Kinetic constants $\left(K_{\mathrm{M}}, v_{\max }\right)$ were obtained from the Michaelis-Menten curves by non-linear fitting (see ESI, Figures S25-S33).

Ammonia addition reaction at preparative scale

In a $100 \mathrm{~mL}$ flask, E. coli Rosetta (DE3) pLysS cells harbouring the $\mathrm{pET19b}$ vector carrying the pcpal L134A mutant gene were resuspended in $6 \mathrm{M} \mathrm{NH}_{4} \mathrm{OH}$-solution $(\mathrm{pH}$ 9.8 adjusted with $\mathrm{CO}_{2}$ ) to give a final $\mathrm{OD}_{600}$ of $\sim 10$. To the cell suspension was added $m$-bromocinnamic acid $1 \mathrm{k}(0.5 \mathrm{~g}, 2.21 \mathrm{mmol})$ at a final concentration of $10 \mathrm{mM}$ and the reaction was incubated at $200 \mathrm{rpm}, 30{ }^{\circ} \mathrm{C}$ for $48 \mathrm{~h}$, with monitoring the conversion values by reversed phase HPLC. When stationary conversions were reached the reaction mixture was acidified to $\mathrm{pH} 1.5$ by dropwise addition of aqueous $\mathrm{H}_{2} \mathrm{SO}_{4}(50 \%$ $\mathrm{w} / \mathrm{v})$. The formed precipitate was removed by centrifugation at $10000 \mathrm{rpm}(10900 \times \mathrm{g})$, $4{ }^{\circ} \mathrm{C}$ for 20 min.; the non-reacted cinnamic acid $1 \mathrm{k}$ was removed by extraction with ethyl 
acetate $(3 \times 10 \mathrm{~mL})$. The amino acid found within the aqueous phase was purified by ion exchange chromatography using Dowex® $50 \mathrm{WX} 2$ resin and $2 \mathrm{M} \mathrm{NH}_{4} \mathrm{OH}$ solution for elution. The fraction containing the final product was evaporated in a centrifugal evaporator affording the pure L-amino acid L-2k $(0.4 \mathrm{~g}, 1.64 \mathrm{mmol}$ and $74.5 \%$ isolation yield, [a] $]_{\mathrm{D}}:-3.9\left(25^{\circ} \mathrm{C}, 10 \mathrm{mg} / \mathrm{mL}\right.$, in $\left.\mathrm{MeOH}\right)$.

\section{Ammonia elimination reaction at preparative scale}

In a $100 \mathrm{~mL}$ flask, E. coli Rosetta (DE3) pLysS cells harbouring the pET19b vector carrying the the pcpal I460V mutant gene were resuspended in $0.1 \mathrm{M} \mathrm{NH}_{4} \mathrm{OH}$ (pH 10 adjusted with $\left.\mathrm{CO}_{2}\right)$ to give a final $\mathrm{OD}_{600}$ of $\sim 10$. To the cell suspension was added the racemic $p$-methylphenylalanine rac-2c $(0.5 \mathrm{~g}, 2.79 \mathrm{mmol})$ in a final concentration of $10 \mathrm{mM}$ and the reactions were incubated at $200 \mathrm{rpm}, 30{ }^{\circ} \mathrm{C}$ for 48 hours, monitoring the conversion values by reversed phase HPLC. When stationary conversions were reached the reaction mixtures were purified using the same method described above in the preparative scale ammonia addition section, yielding the pure D-amino acid D-2c $(0.24 \mathrm{~g}, 1.34 \mathrm{mmol} \text { and } 49 \% \text { isolation yield, [a }]_{\mathrm{D}}:+7.8$ $\left(25^{\circ} \mathrm{C}, 10 \mathrm{mg} / \mathrm{mL}\right.$, in $\left.\mathrm{MeOH}\right)-$ in accordance with data from literature $\left.{ }^{36}\right)$.

\section{HPLC methods for the determination of conversion and enantiomeric excess values}

High performance liquid chromatography (HPLC) analyses were conducted with an Agilent (Santa Clara, CA, USA) 1200, 1260 and 1100 systems. 
For the determination of conversion values samples from biotransformations were injected onto a Gemini NX-C18 column $(150 \times 4.5 \mathrm{~mm} ; 5 \mu \mathrm{m})$, and eluted with a flow rate of 1.0 $\mathrm{mL} \min ^{-1}$, at $25{ }^{\circ} \mathrm{C}$ using different gradients of the mobile phase: $\mathrm{A}: \mathrm{NH}_{4} \mathrm{OH}$ buffer $(0.1 \mathrm{M}, \mathrm{pH}$ 9.0) / B: $\mathrm{MeOH}$ (see detailed description in ESI).

Enantiomeric excess values were determined using a chiral HPLC separation of the rac-2a-l, developed using Crownpak CR-I $(+)$ chiral column $(150 \times 3 \mathrm{~mm} ; 5 \mu \mathrm{m})$ and $\mathrm{HClO}_{4}(\mathrm{pH}=1.5)$ : ACN as mobile phase, at different flow rate (see detailed description in ESI). The absolute configuration of the eluted enantiomers was assessed from their elution order from the chiral CROWNPAK CR-I(+)column, according to the manufacturer's instructions, which was also confirmed by the obtained retention times for commercial $\mathrm{D}-$ and $\mathrm{L}-\mathrm{Phe}$ standards $\left(\mathrm{R}_{\mathrm{t}, \mathrm{D}-\mathrm{Phe}}=3.05\right.$ $\left.\min , \mathrm{R}_{\mathrm{t}, \mathrm{L}-\mathrm{Phe}}=5.03 \mathrm{~min}\right)$.

\section{Crystallisation experiments}

A solution of recombinant PCPAL 1460V/C704S/C716S (10 mg/mL) purified according

to a previously reported procedure ${ }^{28}$, in (20 mM Tris, $100 \mathrm{mM} \mathrm{NaCl}, \mathrm{pH} 8.0$ ) was saturated with substrate $1 \mathrm{f}$ and left to incubate at $4 \square \mathrm{C}$ for $1 \mathrm{~h}$ prior to crystallisation. Crystallization was performed at $4 \square \mathrm{C}$ using the sitting-drop vapor diffusion method. Initial crystallisation conditions were identified using a Peglon broadscreen (Hampton Research) set up in low reservoir Intelli-Plate 93-3 (Art Robbins Instruments) using a Rigaku Phoenix RE Drop setter instrument (Art Robbins Instrument) mixing $100 \mathrm{~nL}$ of 
protein solution with $100 \mathrm{~nL}$ of precipitant. Small crystals were obtained after 2 weeks in condition C6 (0.2 M ammonium acetate, $20 \%$ PEG 3350). Larger crystals were obtained by using larger drops ( $2 \mu \mathrm{L}$ protein and $2 \mu \mathrm{L}$ precipitant) in combination with micro-seeding. A data-set was collected using beamline 103 at the Diamond Light Source. The structure was solved in the space group C2221 via molecular replacement using Phaser with the reported structure of PCPAL (PDB ID: $1 \mathrm{~W} 27^{23}$ ) as a search model. Refinement was carried out using Phenix and iterative fitting using Coot software packages $^{37,38}$. The tetramer, obtained using the symmetry related molecules, contains four active sites which each involve residues of three different enzyme molecules (chain $\mathrm{A}, \mathrm{B}$ and a symmetry related chain $\mathrm{A}$ in Figure $\mathrm{S} 35)$, as reported, e.g., for wt-PCPAL (PDB ID: $1 \mathrm{~W} 27^{23}$ ). In the active site apparently complete post-translational modification of residues 202-204 to 4-methylideneimidazole-5-one (MIO), as characteristic for PAL active sites ${ }^{26}$, was observed.

\section{Conclusions}


The combined results on the activity and selectivity of mutants of PAL from parsley, using a series of mono-substituted phenylalanine and cinnamic acid analogues, reveal the possible active site orientations of substrate aromatic substituents, as function of their $o_{-}, m-, p$ - substitution. In the case of $o$-substituted substrates $w t-P c P A L$ proved to be an efficient biocatalyst, suggesting that, at least, for moderately-sized $o$-substituents there is sufficient space in the wild-type active site. However, substitution of L256 enabled an increase in activity, indicating spatial orientation of $o$-substituents towards this residue. Substituents in the $m$-position, and with an o-methoxy group, are likely orientated towards residue L134. In these cases mutations L134A, or of I460V in the case of electron-poor $m$-substituents, were necessary to provide high catalytic efficiency, suggesting that in these cases steric hindrance occurs within the active site of wild-type enzyme. For $p$-substituted substrates the catalytic properties of wt-PcPAL were significantly increased through substitution of residues F137 and 1460, implying substituent interaction and presumably steric clashes with these active site residues. In accord with the results of the mutational strategy, crystallographic analysis of the binding mode of $p$-methoxy cinnamic acid, at the active site of PCPAL I460V supports 
the proposed orientation of methoxy group towards residue $460 \mathrm{~V}$ and provides the first structure of an active PAL with a ring-substituted substrate-analogue bound at the active site.

The biocatalytic utility of the tailored PALs was demonstrated by the efficient preparative scale synthesis, of D- and L- phenylalanine analogues. The overall results thus provide evidence that structure based engineering of the PAL active site will be productive with respect to producing enzymes of industrial value.

\section{Associated Content}

Supporting Information. Experimental details, tables and figures related to sitedirected mutagenesis, substrate synthesis, activity screens, HPLC methods, kinetic measurement and crystallization studies. This material is available free of charge on the ACS Publications website http://pubs.acs.org.

\section{Acknowledgements}


This work was financed by the Swiss National Science Foundation (SNSF) - project

PROMYS, grant nr. IZ11Z0_166543 - and by the National Authority for Scientific

Research and Innovation (ANCSI) and European Regional Development Fund,

Competitiveness Operational Program 2014-2020 (POC), Priority axis 1, Action 1.1

(project NEMSyB, ID P37_273, Cod MySMIS 103413). JB and CJS thank the Wellcome

Trust for funding. PAL and CJS thank the MRC for funding (Medical Research

Foundation (MRF-145-0004-TPG-AVISO). LP thanks the Higher Education Excellence

Program of the Ministry of Human Capacities in the frame of Biotechnology research area of Budapest University of Technology and Economics (BME FIKP-BIO).

\section{References}




\begin{abstract}
1'Wang Y. S., Fang X., Chen H. Y., Wu B., Wang Z. U., Hilty C., Liu W. R., Genetic Incorporation of Twelve meta-Substituted Phenylalanine Derivatives Using a Single Pyrrolysyl-tRNA Synthetase Mutant, ACS Chem. Biol., 2013, 8, 405-415
\end{abstract}

2 Peters F. B., Brock A., Wang J., Schultz P. G., Photocleavage of the Polypeptide Backbone by 2-Nitrophenylalanine, Chem Biol., 2009, 16, 148-152

3 Tian X., Chen X., Gan L., Hayes J. C., Switzer A. G., Solinsky M. G., Ebetino F. G, Wos J. A., Pinney B. B., Farmer J. A., Crossdoersen D., Sheldon R. J., Synthesis of TicD-Phe $\Psi\left[\mathrm{CH}_{2}-\mathrm{CH} 2\right]$ Isostere and its use in the Development of Melanocortin Receptor Agonists, Bioorg. Med. Chem. Lett., 2006, 16, 1721

${ }^{4}$ Latacz G., Pekala E., Ciopińska A., Kieć-Kononowicz K., Unnatural D-Amino Acids as Building Blocks of New Peptidomimetics, Acta Pol. Pharm., 2006, 63, 430-433

5 Zhang N., Liu L., Shan G., Cai Q., Lei X., Hong B., Wu L., Xie Y., Chen R., Precursor-Directed Biosynthesis of New Sansanmycin Analogs Bearing paraSubstituted-Phenylalanines with High Yields, J. Antibiot., 2016, 69, 765-768 
${ }^{6}$ Wakiec, R., Gabriel, I., Prasad, R., Becker, J. M., Payne, J. W., Milewski, S.

Enhanced Susceptibility to Antifungal Oligopeptides in Yeast Strains Overexpressing ABC Multidrug Efflux Pumps, Antimicrob. Agents Chemother., 2008, 52, 4057-4063

7 Slaninová J., Maletínská L., Vondrášek J., Procházka Z., Magnesium and Biological Activity of Oxytocin Analogues Modified on Aromatic Ring of Amino Acid in Position 2, J. Peptide Sci., 2001, 7, 413-424

${ }^{8}$ Parmeggiani F., Weise N. J, Ahmed S. T., Turner N. J., Synthetic and Therapeutic Applications of Ammonia-Lyases and Aminomutases, Chem. Rev., 2018, 118, 73-118

9 de Lange B., Hyett D. J., Maas P. J. D., Mink D., van Assema F. B. J, Sereinig N., de Vries A. H. M., de Vries J. G., Asymmetric Synthesis of (S)-2-Indolinecarboxylic Acid by Combining Biocatalysis and Homogeneous Catalysis, ChemCatChem, 2011, 3, 289292. 
10 Gloge A., Zoń J., Kővári Á., Poppe L., Rétey J., Phenylalanine Ammonia-Lyase:

The Use of its Broad Substrate Specificity for Mechanistic Investigations and Biocatalysis - Synthesis of L-Arylalanines, Chem. Eur. J., 2000, 6, 3386-3390

11 Paizs C., Katona A., Rétey J., The Interaction of Heteroarylacrylates and Alanines with Phenylalanine Ammonia-Lyase from Parsley, Chem. Eur. J., 2006, 12, 2739-2744

12 Paizs C., Toșa M. I., Bencze L. C., Brem J., Irimie F. D., Rétey J., 2-amino-3-(5phenylfuran-2-yl)propionic Acids and 5-phenylfuran-2-ylacrylic Acids are Novel Substrates of Phenylalanine Ammonia-Lyase, Heterocycles, 2010, 82, 1217-1228

${ }^{13}$ Bartha-Vári J. H., Toșa M. I., Irimie F. D., Weiser D., Boros Z., Vértessy B. G., Paizs C., Poppe L., Immobilization of Phenylalanine Ammonia-Lyase on Single-Walled Carbon Nanotubes for Stereoselective Biotransformations in Batch and ContinuousFlow Modes, ChemCatChem, 2015, 7, 1122-1128

${ }^{14}$ Bartha-Vári J. H., Bencze L. C., Bell E., Poppe L., Katona G., Irimie F. D., Paizs C., Toșa M. I, Aminated Single-Walled Carbon Nanotubes as Carrier for Covalent 
Immobilization of Phenylalanine Ammonia-Lyase, Period. Polytech., Chem. Eng., 2017,

$61,59-66$

${ }^{15}$ Filip A., Nagy E. Z. A., Tork S. D., Bánóczi G., Toșa M. I, Irimie F.D., Poppe L.,

Csaba P., Bencze L. C., Tailored Mutants of Phenylalanine Ammonia-Lyase from Petroselinum crispum for the Synthesis of Bulky L- and D-Arylalanines, ChemCatChem,

2018, 10, $2627-2633$

16 Xue Z., McCluskey M., Cantera K., Sariaslani F. S., Huang L., Identification, Characterization and Functional Expression of a Tyrosine Ammonia-Lyase and its Mutants from the Photosynthetic Bacterium Rhodobacter sphaeroides, J. Ind. Microbiol. Biotechnol., 2007, 34, 599-604

17 Louie G. V., Bowman M. E., Moffitt M. C., Baiga T .J., Moore B. S., Noel J. P. Structural Determinants and Modulation of Substrate Specificity in PhenylalanineTyrosine Ammonia Lyases, Chem. Biol., 2006, 13, 1327-1338 
18 Bartsch S., Bornscheuer U. T., Mutational Analysis of Phenylalanine Ammonia Lyase to Improve Reactions Rates for Various Substrates, Protein Eng. Des. Sel., 2010, 23, 929-933

19 Ahmed S. T., Parmeggiani F., Weise N. J., Flitsch S. L., Turner N. J., Chemoenzymatic Synthesis of Optically Pure L- and D-Biarylalanines Through Biocatalytic Asymmetric Amination and Palladium- Catalyzed Arylation, ACS Catal., $2015,5,5410-5413$

${ }^{20}$ Ahmed S. T., Parmeggiani F., Weise N. J., Flitsch S. L., Turner N. J., Engineered Ammonia Lyases for the Production of Challenging Electron-Rich L-Phenylalanines, ACS Catal., 2018, 8, 3129-3132

${ }^{21}$ Bencze L. C., Filip A., Bánóczi G., To $\square$ a M. I., Irimie F. D., Gellért Á., Poppe L., Paizs C., Expanding the Substrate Scope of Phenylalanine Ammonia-Lyase from Petroselinum crispum Towards Styrylalanines, Org. Biomol. Chem. 2017, 15, 37173727 


\begin{abstract}
22 Bánóczi G., Szabó C., Bata Z., Hornyánszky G., Poppe L., Structural modeling of phenylalanine ammonia-lyases and related mio-containing enzymes - an insight into thermostability and ionic interactions, Stud. Univ. Babes-Bol. Ser. Chem, 2015, 60, 213-
\end{abstract} 228.

${ }^{23}$ Ritter H., Schulz G.E., Structural Basis for the Entrance into the Phenylpropanoid Metabolism Catalyzed by Phenylalanine Ammonia-Lyase, Plant Cell, 2004, 16, 34263436

${ }^{24}$ Calabrese J. C., Jordan D. B., Boodhoo A., Sariaslani S., Vannelli T., Crystal Structure of Phenylalanine Ammonia Lyse: Multipled Helix Dipoles Implicated in Catalysis, Biochemistry, 2004, 43, 11403-11416

25 Bartsch S., Bornscheuer U. T., A Single Residue Influences the Reaction Mechanism of Ammonia Lyases and Mutases, Angew. Chem. Int. Ed., 2009, 48, 33623365 
26 Poppe L., Rétey J., Friedel-Crafts-Type Mechanism for the Enzymatic Elimination of Ammonia from Histidine and Phenylalanine, Angew. Chem. Int. Ed., 2005, 44, 36683688

27 Pilbák S., Tomin A., Rétey J., Poppe L., The Essential Tyrosine-Containing Loop Conformation and the Role of the C-Terminal Multi-Helix Region in Eukaryotic Phenylalanine Ammonia-Lyases, FEBS J., 2006, 273, 1004-1019

${ }^{28}$ Dima N. A., Filip A., Bencze L. C., Oláh M., Sátorhelyi P., Vértessy B. G., Poppe L., Paizs C., Expression and Purification of Recombinant Phenylalanine Ammonia-Lyase from Petroselinum crispum, Stud. Univ. Babes-Bolyai Ser. Chem., 2016, 61, 21-34

\author{
29 Wang L., Gamez A., Archer H., Abola E. E., Sarkissian, C. N., Fitzpatrick P., Wendt \\ D., Zhang Y., Vellard M., Bliesath J., Bell S. M., Lemontt J. F., Scriver C. R., Stevens R. \\ C. Structural and Ciochemical Characterization of the Therapeutic Anabaena variabilis \\ Phenylalanine Ammonia Lyase, J. Mol. Biol., 2008, 380, 623-635
}


${ }^{30}$ Weise N. J., Ahmed S.T., Parmeggiani F., Galman J. L., Dunstan M.S., Charnock S.J., Leys D., Turner N. J., Zymophore Identification Enables the Discovery of Novel Phenylalanine Ammonia Lyase Enzymes, Sci. Rep., 2017, 7, 13691-13691

${ }^{31}$ Feng L., Wanninayake U., Strom S., Geiger J., Walker K. D. Mechanistic, Mutational and Structural Evaluation of a Taxus Phenylalanine Aminomutase, Biochemistry, 2011, $50,2919-2930$

32 Piscotta F. J., Tharp J. M., Liu W. R., Link A. J., Expanding the Chemical Diversity of Lasso Peptide MccJ25 with Genetically Encoded Non-Canonical Amino Acids, Chem.

Commun., 2015, 51, 409-412

33 Meng K., Shim P., Wanga Q., Zhao S., Gu T., Kahsai A. K., Ahn S., Chen X., Bioorg. Med. Chem. Lett., 2018, 26, 2320-2330

${ }^{34}$ Hwang T. L., Hung C.H., Hsu C. Y., Huang Y. T, Tsaic Y. C., Hsieh P. W., Org. Biomol. Chem., Design and Synthesis of Tryptophan Containing Dipeptide Derivatives as Formyl Peptide Receptor 1 Antagonist, 2013, 11, 3742-3755 
35 Dong L., Marakovits J., Hou X., Guo C., Greasley S., Dagostino E., Ferre R., Johnson M. C., Kraynov E., Thomson J., Pathak V., Murray B. W., Structure-Based Design of Novel Human Pin1 Inhibitors (II), Bioorg. Med. Chem. Lett., 2010, 20, 22102214

36 Moran-Ramallal R., Liz R., Gotor V., Enantiopure trans-3-Arylaziridine-2carboxamides: Preparation by Bacterial Hydrolysis and Ring-Openings Toward Enantiopure, Unnatural D-a-Amino Acids, J. Org. Chem., 2010, 75, 6614-6624

37 Adams P.D., Grosse-Kunstleve R. W., Hung L.W., loerger T. R., McCoy A. J., Moriarty N. W., Read R. J., Sacchettini J. C., Sautera N. K., Terwilligerf T. C., PHENIX: Building New Software for Automated Crystallographic Structure Determination, Acta Crystallogr. Sect. D Biol. Crystallogr., 2002, 58, 1948-1954

${ }^{38}$ Emsley P., Lohkamp B., Scott W. G., Cowtand K., Features and Development of Coot, Acta Crystallogr. Sect. D Biol. Crystallogr., 2010, 66, 486-501

For Table of Contents Only (TOC graphic) 
1

2

3

4

5

6

7

8

9

10

11

12

13

14

15

16

17

18

19

20

21

22

23

24

25

26

27

28

29

30

31

32

33

34

35

36

37

38

39

40

41

42

43

44

45

46

47

48

49

50

51

52

53

54

55

56

57

58

59

60

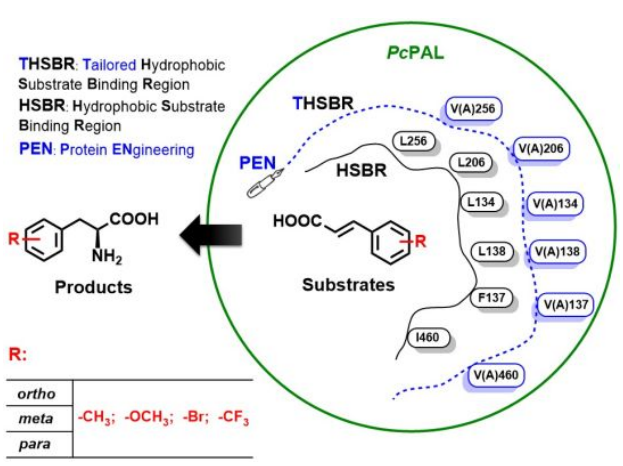


a)

\section{Ammonia elimination reaction}

Kinetic resolution<smiles>[R]CC(N)C(=O)O</smiles>

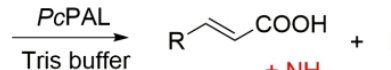
$\mathrm{pH} 8.8$

rac-2

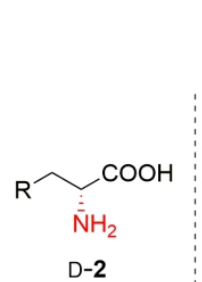

Ammonia addition reaction

Asymmetric synthesis

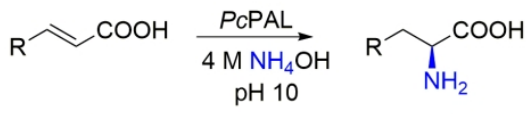

1

L-2

b)

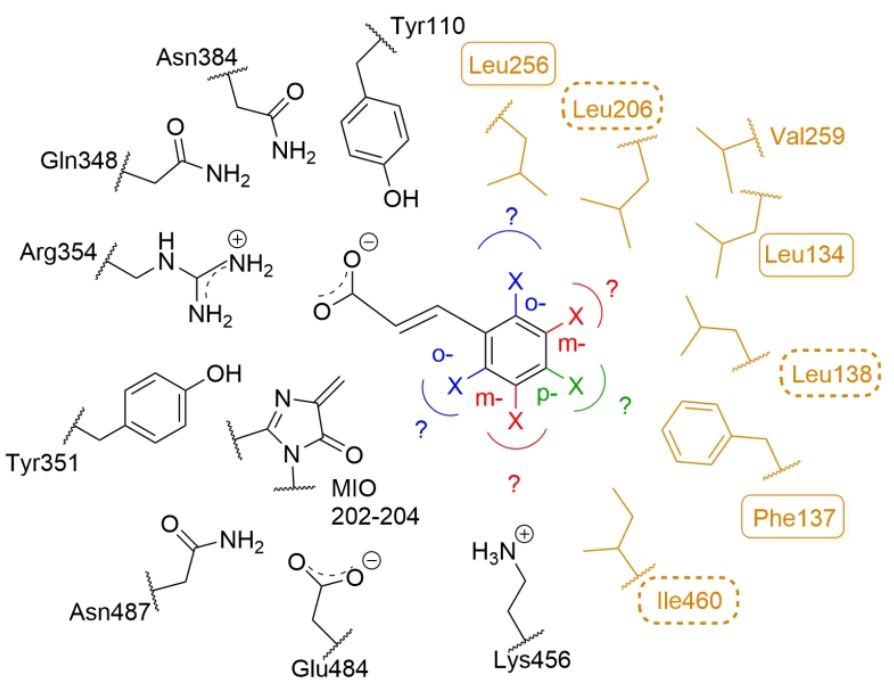

Figure 1. PCPAL catalysis and active site residues a) Ammonia addition and elimination reactions catalyzed by PCPAL. b) An active site model of PCPAL15, (PDB ID: 1W27) with modeled trans-cinnamic acid indicating possible interactions with the hydrophobic binding pocket (orange). Predicted orientations of aryl ring substituents are blue (ortho-), red (meta-), and green (para-). The post-translationally produced 3,5dihydro-5-methylene-4H-imidazol-4-one (MIO) prosthetic group and the polar region of active site is also shown (black). Residues placed in boxes were selected for alanine and valine scanning with the aim of accommodating of ring substituents. Side chains in dashed boxes are positioned below the plane of the substrate's aromatic ring, while those with normal boxes are positioned above this plane.

$189 \times 155 \mathrm{~mm}(300 \times 300 \mathrm{DPI})$ 


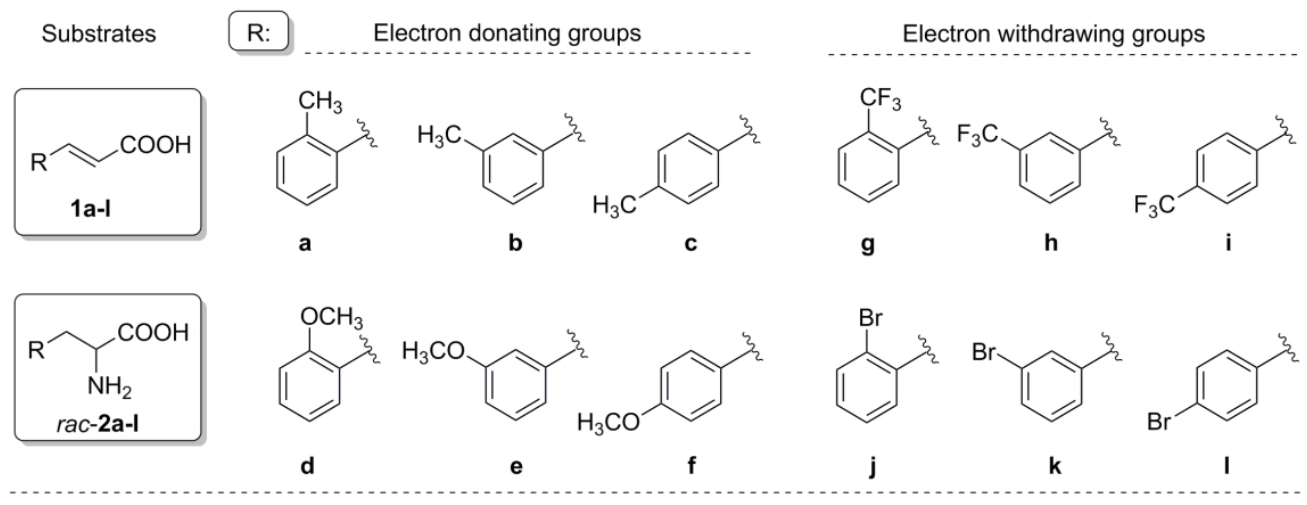

Figure 2. Substrates with monosubstituted phenyl moieties bearing electron donating or electron withdrawing groups in all positions of the aromatic ring for probing the PCPAL mutant library.

$190 \times 72 \mathrm{~mm}(300 \times 300$ DPI $)$ 


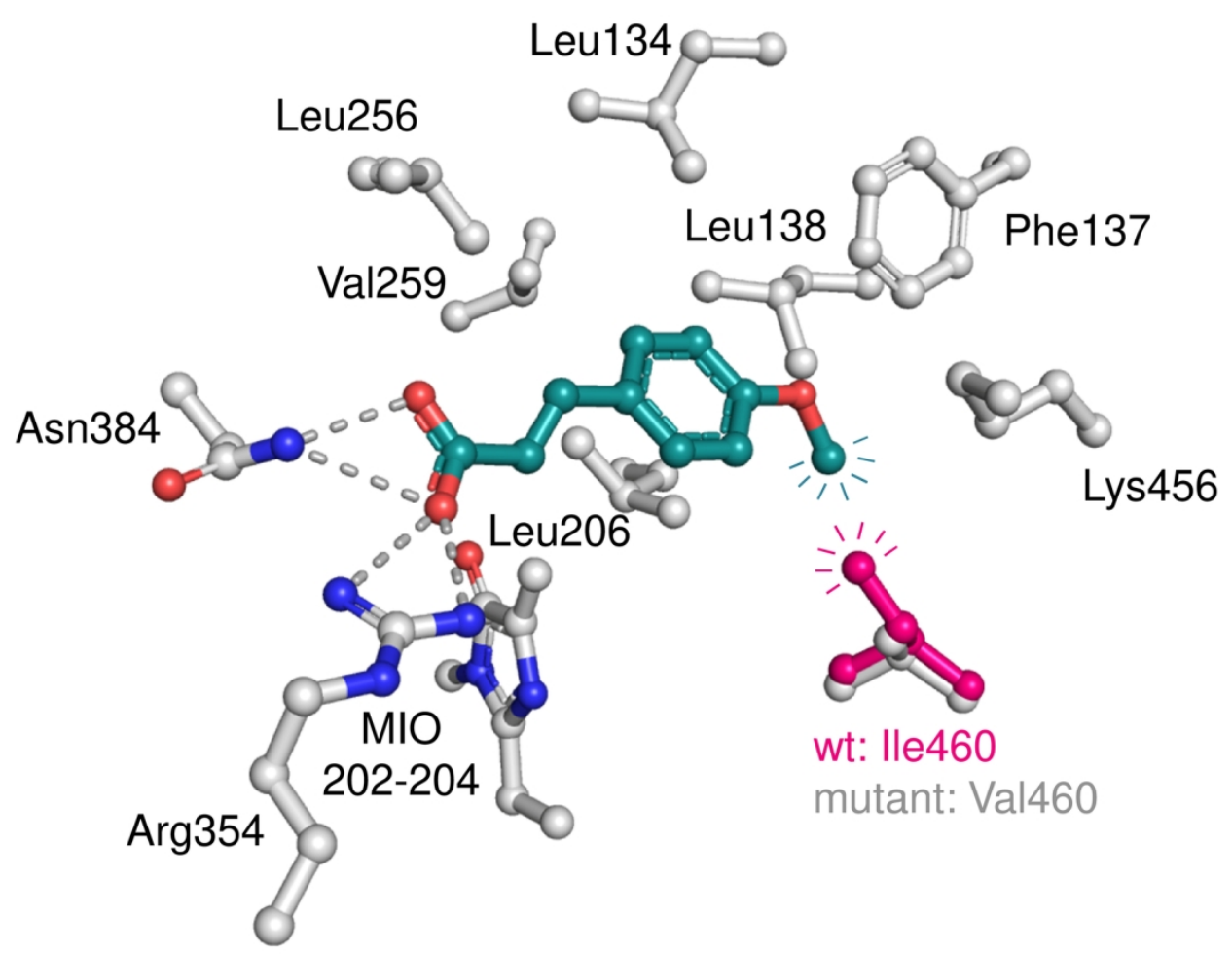

Figure 3: View of p-methoxy-cinnamic acid $1 \mathrm{f}$ at the active site of PcPAL I460V (PDB ID: 6RGS). Side chains of active site residues (white) involved in substrate binding, including those in the hydrophobic pocket are shown. The side chain of I460 as observed in the active site of wt-PcPAL (PDB ID: 1W27) is overlaid in magenta. The I460V substitution prevents the indicated steric clash of this side chain with the $p$-substituent of the substrate. See Figure S36 for full overlay of the two active sites.

$145 \times 111 \mathrm{~mm}(300 \times 300 \mathrm{DPI})$ 

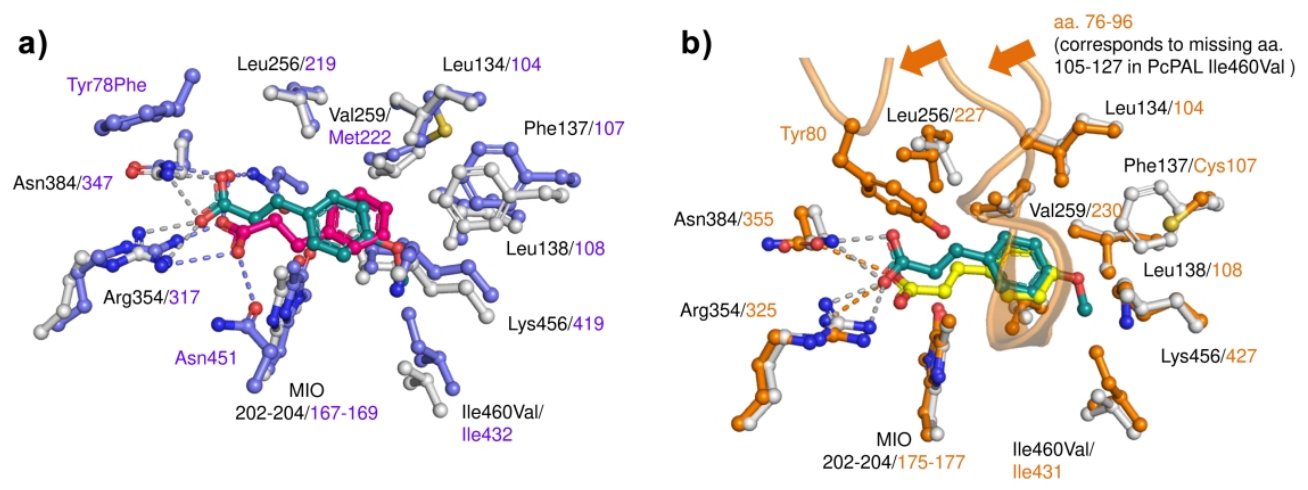

Figure 4. Overlay of active sites of I460V PCPAL - p-methoxy cinnamic acid 1f (cyan) complex and reported structures: a) overlay with structure of Y78F/C503S/C565S AvPAL with "cinnamate", apparently refined into hydro-cinnamic acid (magenta) (PDB ID: 5LTM)30 b) overlay with the active site of TCPAM in complex with cinnamic acid (yellow) (PDB ID: 3NZ4)31, amino acids 76-96 are located in the active site and indicated as cartoon.

$342 \times 127 \mathrm{~mm}(300 \times 300 \mathrm{DPI})$ 


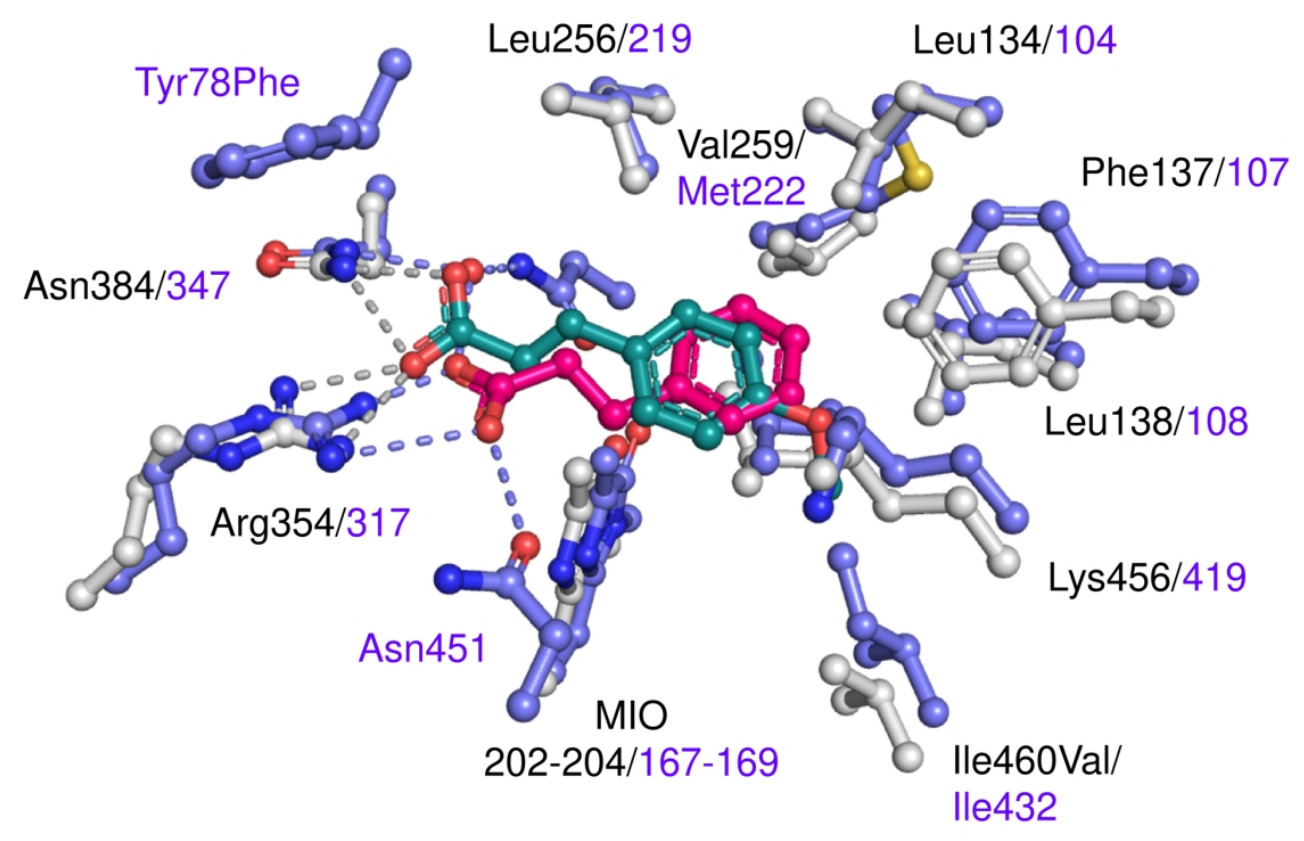

Individual image for Figure $4 a$, if needed.

$165 \times 106 \mathrm{~mm}$ ( $300 \times 300$ DPI) 


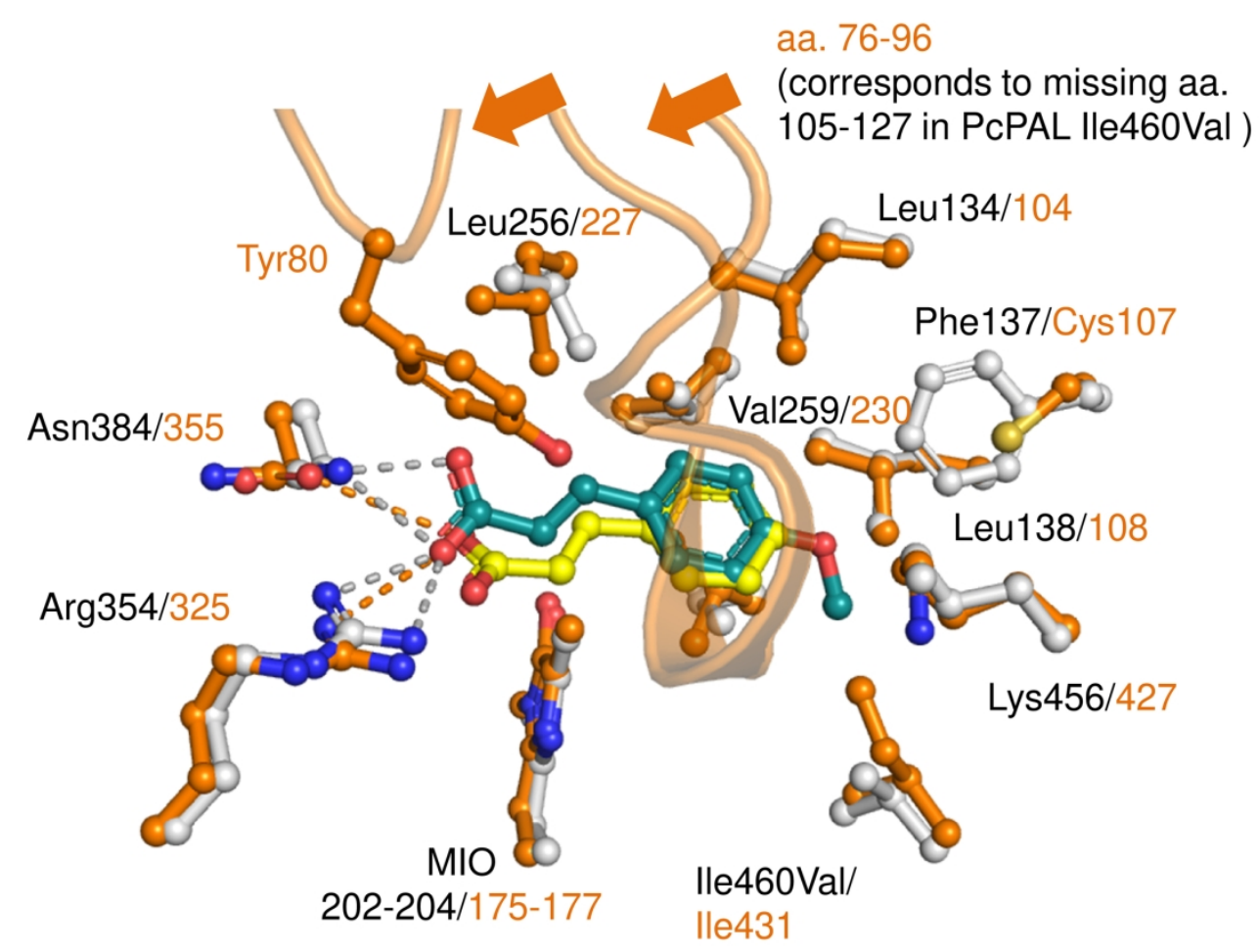

Inidvidual image for Figure 4b, if needed.

$170 \times 127 \mathrm{~mm}(300 \times 300$ DPI $)$ 
a)

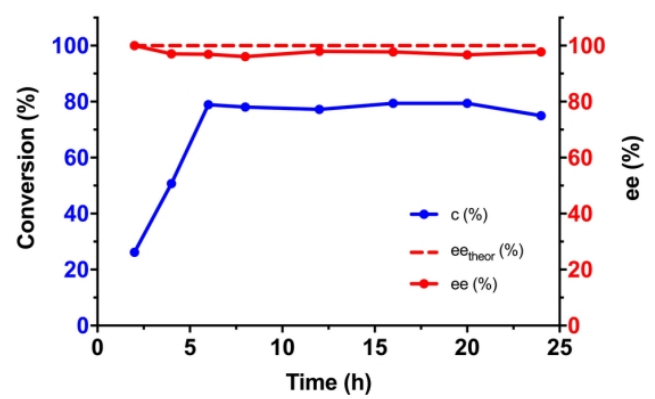

b)

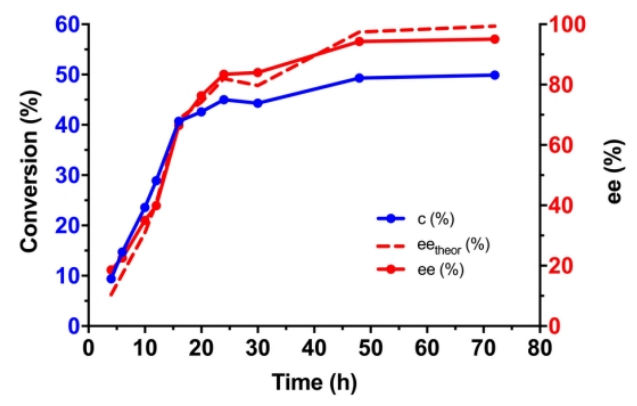

Figure 5. Conversion and enantiomeric excess progression curves for a) the ammonia addition onto $\mathrm{m}$ - $\mathrm{Br}$ cinnamic acid $1 \mathrm{k}$ using L134A PCPAL and for b) the ammonia elimination from rac-p-methyl-phenylalanine rac-2c using I460V PCPAL.

$703 \times 238 \mathrm{~mm}(72 \times 72 \mathrm{DPI})$ 


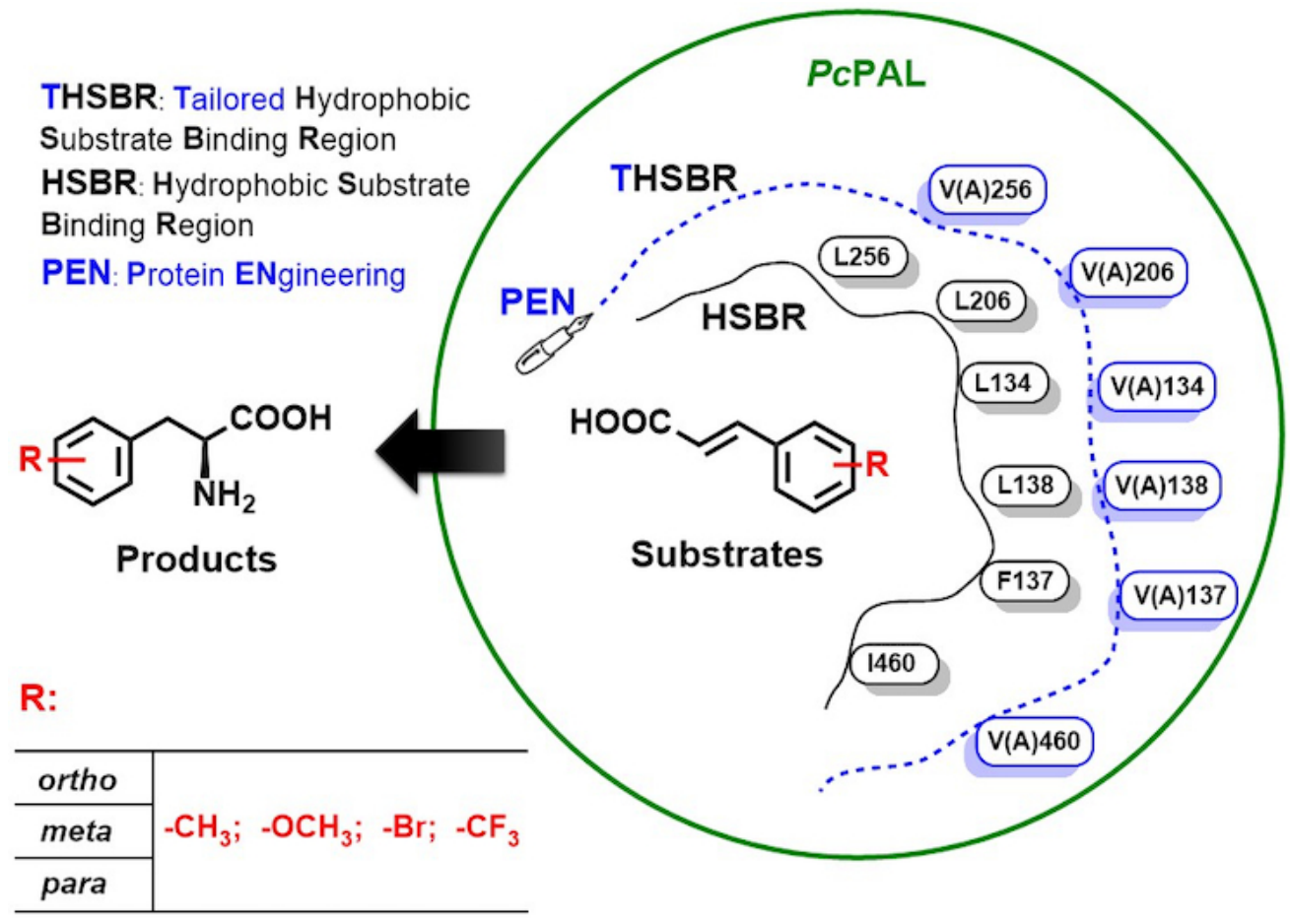

For Table of Contents Only (TOC graphic)

$62 \times 44 \mathrm{~mm}(300 \times 300 \mathrm{DPI})$ 